\title{
Using a cloud electrification model to study relationships between lightning activity and cloud microphysical structure
}

\author{
M. Formenton ${ }^{1, *}$, G. Panegrossi ${ }^{1}$, D. Casella ${ }^{1}$, S. Dietrich ${ }^{1}$, A. Mugnai ${ }^{1}$, P. Sanò ${ }^{1}$, F. Di Paola ${ }^{2}$, H.-D. Betz ${ }^{3}$, C. Price ${ }^{4}$, \\ and Y. Yair ${ }^{5}$ \\ ${ }^{1}$ Institute of Atmospheric Sciences and Climate (ISAC), Italian National Research Council (CNR), Roma, Italy \\ ${ }^{2}$ Institute of Methodologies for Environmental Analysis (IMAA), Italian National Research Council (CNR), \\ Tito Scalo (PZ), Italy \\ ${ }^{3}$ Physics Department, University of Munich, Garching, and Nowacast GmbH, Munich, Germany \\ ${ }^{4}$ Department of Geophysical, Atmospheric and Planetary Science, Tel-Aviv University, Ramat Aviv, Israel \\ ${ }^{5}$ Department of Life and Natural Sciences, Open University, Ra'anana, Israel \\ *now at: Hawaii Institute of Geophysics and Planetology, University of Hawaii at Manoa, Honolulu, Hawaii, USA
}

Correspondence to: G. Panegrossi (g.panegrossi@isac.cnr.it)

Received: 2 August 2012 - Published in Nat. Hazards Earth Syst. Sci. Discuss.: -

Revised: 1 March 2013 - Accepted: 4 March 2013 - Published: 24 April 2013

\begin{abstract}
In this study a one-dimensional numerical cloud electrification model, called the Explicit Microphysics Thunderstorm Model (EMTM), is used to find quantitative relationships between the simulated electrical activity and microphysical properties in convective clouds. The model, based on an explicit microphysics scheme coupled to an ice-ice noninductive electrification scheme, allows us to interpret the connection of cloud microphysical structure with charge density distribution within the cloud, and to study the full evolution of the lightning activity (intracloud and cloud-toground) in relation to different environmental conditions. Thus, we apply the model to a series of different case studies over continental Europe and the Mediterranean region. We first compare, for selected case studies, the simulated lightning activity with the data provided by the ground-based Lightning Detection Network (LINET) in order to verify the reliability of the model and its limitations, and to assess its ability to reproduce electrical activity consistent with the observations. Then, using all simulations, we find a correlation between some key microphysical properties and cloud electrification, and derive quantitative relationships relating simulated flash rates to minimum thresholds of graupel mass content and updrafts. Finally, we provide outlooks on the use of such relationships and comments on the future development of this study.
\end{abstract}

\section{Introduction}

In recent years the interest in lightning has been increasing mainly because of the need to monitor the conditions leading to severe weather (Williams et al., 1999; Schultz et al., 2011) and sometimes to flash floods (Price et al., 2011). Since lightning data give a direct and precise indication of convective activity in clouds, their integration with remote sensing cloud observing systems can be very useful both for diagnostic and prognostic purposes.

There are numerous studies on the relationships between precipitation and lightning, which are based either on the use of ground lightning detection networks around the globe, or on the measurements taken from space-borne instruments such as the Lightning Imaging Sensor (LIS) onboard the Tropical Rainfall Measuring Mission (TRMM) satellite (http://trmm.gsfc.nasa.gov/). For example, the introduction section in the paper by Gungle and Krider (2006) gives a full review of the current understanding of the relationships between cloud-to-ground (CG) lightning and precipitation, which are strongly coupled in convective storms. Notably, these relationships are highly variable depending on the geographical thunderstorm characteristics - e.g., Tapia et al. (1998), Soula et al. (1998), Lang and Rutledge (2002), Zhou et al. (2002), Latham et al. (2004), Cecil et al. (2005), Goodman et al. (2007). 
Specifically, Tapia et al. (1998) proposed a model for regression of convective rainfall based on a study of several storms that occurred over Florida. They used CG lightning data from the US National Lightning Detection Network (NLDN) compared with radar rainfall estimations to infer the regression model and calculated the key parameter rainfall yield/flash (i.e., the ratio between the total water fallen during the storm divided by the total amount of detected flashes), finding values from 20 to $360\left(10^{6} \mathrm{~kg}\right.$ flash $\left.^{-1}\right)$. Later, Soula and Chauzy (2001) performed a similar study over Paris using a VHF lightning network, capable of discriminating between intra-cloud (IC) and CG lightning, and compared the measurements with radar data. They found a rainfall yield/flash $\left(\mathrm{m}^{3}\right.$ flash $\left.^{-1}\right)$ value ranging from 1 to 100 $\left(10^{6} \mathrm{~kg} \mathrm{flash}^{-1}\right)$. Kempf and Krider (2003) studied the relationship between rain and lightning for the case of the 1993 flood in the Mississippi Basin. They used the CG lightning data from the US NLDN and surface rainfall as reported by the National Weather Service cooperative observers. By correcting their data for an imperfect detection efficiency, they found a daily precipitation volume per reported CG flash (CGF) of about $4.6\left(10^{5} \mathrm{~m}^{3} \mathrm{CGF}^{-1}\right)$ over the greater Upper Mississippi River basin, with a seasonal mean rain volume of about $1.3\left(10^{5} \mathrm{~m}^{3} \mathrm{CGF}^{-1}\right)$. Pineda et al. (2007) made similar measurements during nine convective events over Catalonia in the summer 2004. They used total lightning data collected by the Meteorological Service of Catalonia lightning detection network based on SAFIR (Surveillance et Alerte Foudre par Interférometrie Radioélectrique) sensors, which is also able to discriminate between CG and IC lightning, and found a rainfall to total lightning ratio similar to Soula and Chauzy (2001), roughly 10-90 $\left(10^{3} \mathrm{~m}^{3} \mathrm{flash}^{-1}\right)$. Price and Federmesser (2006) used TRMM data to study the relationships between rainfall and total lightning over the eastern and central Mediterranean Sea. They found a very high monthly and seasonal correlation $(0.81-0.98)$ for a rainfall yield/flash between 250 and $970\left(10^{6} \mathrm{~kg}_{\text {flash }}^{-1}\right)$.

In essence, all these studies show a large variability of the water volume/flash ratio. Petersen et al. (2005) pointed out that while the relationship between rainfall and lightning is highly regime dependent, a more solid relationship can be found between lightning and ice microphysics. In their study they used the cloud ice microphysics information available from the Precipitation Radar (PR) onboard TRMM (2A25 PR product) to find global relationships between ice water content and lightning activity as observed by the LIS instrument onboard TRMM. They found that on a global scale the relationship between columnar precipitation ice mass and lightning flash density is invariant between land, ocean and coastal regimes (in contrast to rainfall), suggesting that the physical assumptions of precipitation-based charging and mixed phase precipitation development are robust. Adamo et al. (2009) analyzed the so-called precipitation feature database, which had been developed at the University of Utah using concurrent observations of the LIS,
PR and TRMM Microwave Imager (TMI) instruments onboard TRMM, for a 3-yr period (December 1997 through November 2000) over the southern Mediterranean region. They found that depending on season, there are marked relationships between different flash rate regimes and the vertical PR profiles, which can be useful in determining cloud and precipitation properties when lightning data are available but there are no radar and/or other remote sensing data. Katsanos et al. (2007) carried out a study on the relationships between lightning activity reported by the ZEUS lighting detection network and microphysical parameters of clouds simulated with the nonhydrostatic MM5 meteorological model, for a number of cases over the central and eastern Mediterranean. (The ZEUS lightning network provided by the National Observatory of Athens is a long-range lightning detection network that retrieves lightning location with accuracy to the order of 4-5 km (Lagouvardos et al., 2009) by means of the arrival time difference (ATD) triangulation technique (Kotroni and Lagouvardos, 2008).) Their analysis showed that the temporal distribution of lightning is not well correlated with convective rainfall, while it is well correlated with the simulated concentrations of solid hydrometeors, particularly during the development stage of the storms. Pessi and Businger (2009) explored the relationship between lightning measured from LIS and from a ground network of detectors installed on islands of the North Pacific, and the precipitation and hydrometeor profiles obtained from the TRMM PR. They found a logarithmic increase of flash rates with increase of convective rainfall, as well as of other storm characteristics such as precipitable ice path, radar reflectivity, and storm height, for winter and summer storms in the northern Pacific Ocean. The dependence on cloud depth and, by inference, on the size of the mixed-phase region within the cloud where charge generation and separation occur was already noted by Price and Rind (1992), who showed a global 5th power dependence of flash density on the cloud vertical height. Deierling and Petersen (2008) and Deierling et al. (2008) used a Doppler and dual-polarimetric radar as a source of information of ice distribution and updraft in clouds, in conjunction with lightning data collected in northern Alabama and Colorado/Kansas during two field campaigns. They found good relationships of the total lightning activity with precipitating and nonprecipitating ice mass and estimated fluxes, as well as with updraft volume in the charging zone (i.e., for temperatures colder than $-5^{\circ} \mathrm{C}$ ), and found that these relationships are relatively invariant between different climate conditions.

These studies confirm that because of the nature of the electrification processes in clouds, lightning is directly and strongly related to ice microphysics, while its relationship to precipitation is less clear and regime dependent. Thus, it is worth investigating more in detail the mechanisms of the electrification processes, in order to find quantitative relationships between lightning flashes and cloud properties directly connected with them, such as precipitating and nonprecipitating ice mass content and cloud updrafts. In turn, 
this would certainly favor the use of lightning measurements to infer the connected cloud properties and even to estimate precipitation indirectly, once the regime of the convection and the characteristics of the cloud are identified.

Cloud electrification models allow the study of the relationships between lightning and cloud properties, during the whole evolution of convective clouds and for different climate conditions. This is a relatively young topic of research and it is still evolving from 1-D models incorporating explicit microphysics and cloud electrification processes (Norville et al., 1991; Solomon et al., 2005), through more recent 3-D mesoscale models with lightning activity parameterization (e.g., Yair et al., 2010; Lynn et al., 2012), to explicit 3-D electrification models (e.g., Helsdon et al., 1992; MacGormann et al., 2001; Mansell et al., 2002; Barthe et al., 2012). As compared to 1-D models, 3-D models can provide better and more realistic renditions of thunderstorms. However, their high computation time requirements are often controlled at the expense of the microphysics representation - i.e., bulk microphysics schemes are generally used instead of explicit microphysics schemes. In any case, for all models the challenge is to find a compromise between the level of complexity of all simulation components (i.e., dynamics, microphysics, electrification) and a realistic representation of lightning activity.

In this study we use the 1-D Explicit Microphysics Thunderstorm Model (EMTM), developed by Solomon (1997) (see also Solomon et al., 2005), to investigate and interpret cloud electrification processes through the use of explicit representation of the size dependent microphysical processes and the inclusion of lightning parameterization as described in Solomon and Baker (1996). Following the approach of Solomon et al. (2003) and Adamo et al. (2003), we search for quantitative relationships between the microphysical properties and electrical activity of the simulated convective clouds. The long-term goal of this study is to use these relationships for other applications (e.g., precipitation retrieval from remote sensing observations) in which lightning observations are used to infer cloud microphysical properties.

Thanks to the high computational efficiency of this model, we were able to perform several simulations of different case studies, as well as sensitivity tests on the impact of varying cloud and meteorological parameters. In addition, we use lightning observations from the LINET lightning detection network (Betz et al., 2004, 2007, 2008, 2009), with over 120 sensors over Europe (covering also Italy), to explore the ability of the EMTM model to reproduce lightning activity under different environmental conditions, so as to assess if it is a reliable tool for microphysics-electrification cloud classification. It is worth noting that the comparison with real data is made not in order to find a perfect correspondence between the real and the simulated cells but to find analogies in reproducing the main characteristics of the electrical activity, such as the sensitivity of the flash rate to environmental conditions, and the temporal evolution of the IC and CG activity.

The paper is organized as follows. In Sect. 2 the EMTM and the model initialization procedure are described; Sect. 3 is dedicated to the description of the case studies and of the LINET network; in Sect. 4 the comparison strategy with the LINET network data is discussed, and the results of the modeled lightning activity verification are presented; Sect. 5 is dedicated to a detailed discussion of the results of the model simulations for two selected case studies and to the derivation of quantitative relationships between the microphysical and dynamical properties of the modeled clouds and their lightning activity; the conclusions follow in Sect. 6.

\section{The EMTM model}

This study is based on using the 1-D EMTM numerical cloud model involving explicit microphysics and cloud electrification processes, which was developed by Solomon (1997) see also Solomon et al. (2005). The EMTM model is computationally very efficient because of its dynamical framework, and at the same time, since charge transfer mechanisms are sensitive to particle size (Saunders et al., 1991), the explicit microphysics and electrical scheme generates a good representation of the electrical activity in clouds. The geometric simplicity allows for the inclusion of a lightning parameterization (Solomon and Baker, 1996), whereas this task becomes difficult at higher dimensions (3-D models). We here describe the main features of the model while, for further details, the reader is referred to the original references.

The dynamics in EMTM is based on Asai and Kasahara (1967) and Yau (1980). The model domain is axisymmetric, consisting of three communicating coaxial cylinders: inner and outer cloudy regions within an unsaturated environment (see Fig. 1). EMTM retains all the original dynamic equations of Taylor (1989), where the temperature and velocity fields drive the microphysics in the inner cloudy region. The inclusion of the outer cloudy region allows for a better representation of horizontal processes such as mixing between the cloud and the environment. In the EMTM, the parameterized microphysics of Taylor (1989) is replaced with the explicit microphysics used by Norville et al. (1991). The evolution of water and ice microphysical distributions is explicitly calculated. Water and ice particle masses are defined on a common grid, and discretized into 80 mass bins. Cloud condensation nuclei and ice condensation nuclei are assumed to be spherical with radii of $0.25 \mu \mathrm{m}$. The microphysical processes that are included are growth by deposition, riming and collection, melting, drop breakup, and primary glaciation and secondary ice production via the HallettMossop process (Hallett and Mossop, 1974). In addition, warm rain processes have been included following Norville et al. (1991). 


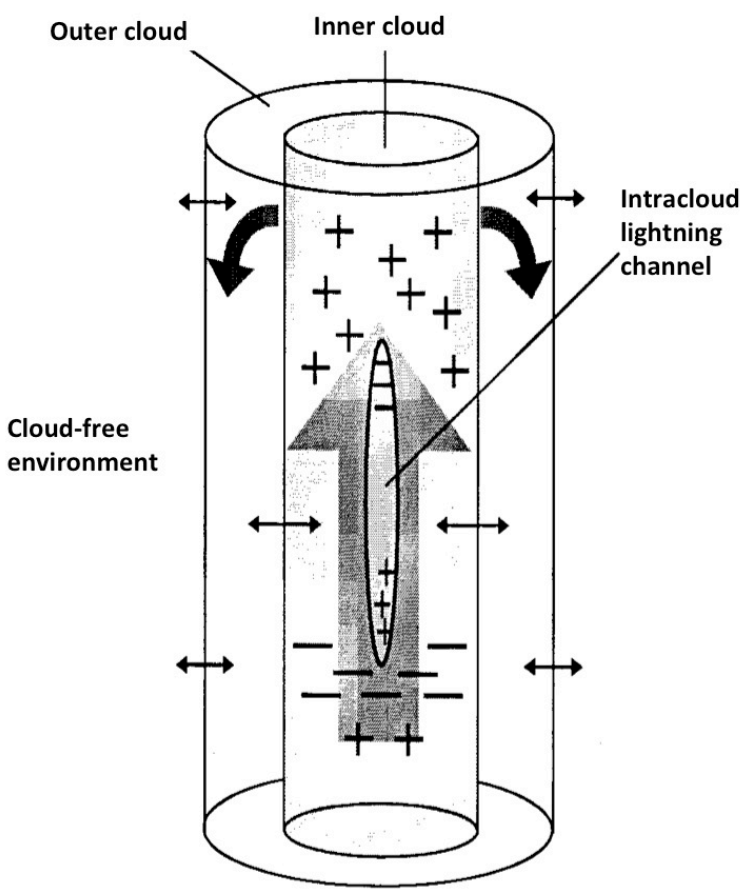

Fig. 1. Schematic diagram of the model geometry with two connecting cloudy cylinders.

Several conceptual models of cloud charge separation are present in literature (e.g., Wilson, 1929; Chalmers, 1967; Jennings, 1975). In this study an electrification scheme based on the noninductive ice-ice process is used (Reynolds et al., 1957; Saunders et al., 1991; Jayaratne et al., 1983; Mason and Dash, 2000; Nelson and Baker, 2003), in which the sensitivity of the charge transfer mechanism to particle size can be adequately represented (Saunders et al., 1991; Solomon et al., 2005; Mansell et al., 2010). Several parameterizations of the noninductive ice-ice process exist (e.g., Takahashi, 1978; Gardiner et al., 1985; Brooks et al., 1997; Saunders and Peck, 1998), and several studies have shown that storm electrification (i.e., cloud polarity and the lightning characteristics) is highly sensitive to this parameterization (e.g., Mansell et al., 2005; Kuhlman et al., 2006; Barthe and Pinty, 2007). Takahashi (1978) and Saunders et al. (1991) have shown that magnitude and sign of the charge transferred to each colliding particle are strong functions of liquid water content and temperature. These authors also showed that application of various noninductive charging schemes to several convective storms results in a storm electrification variability that heavily depends on cloud dynamics and microphysics; and that, even under the same dynamical and microphysical conditions, the electrical polarity and the lightning activity are highly dependent on the noninductive parameterization that is used.

In the EMTM, based on observational evidence and model results by several authors (Gardiner et al., 1985; Dye et al.,
1989; Norville et al., 1991), it is assumed that the dominant charge transfer mechanism involves collisions between ice crystals and graupel particles or soft hail pellets - see also Takahashi (1978), Jayaratne et al. (1983), Baker et al. (1987), and Saunders et al. (1991). This mechanism requires the coexistence of ice, graupel, and supercooled liquid water in the so-called charging zone (CZ) - defined here according to Saunders (2008) as the vertical layer between $0{ }^{\circ} \mathrm{C}$ and $-25^{\circ} \mathrm{C}$. When ice crystals and graupel particles collide, the charged graupel are either suspended within the $\mathrm{CZ}$ or sediment downward depending on their fall velocity as compared to the updraft velocity in the $\mathrm{CZ}$, while the ice crystals, charged by the opposite sign with respect to graupel, are carried upward in the cloud. This process can separate enough charge to generate the electric fields that are observed within lightning producing clouds (Norville et al., 1991; Ziegler et al., 1991).

In essence, the instantaneous charge separation rate and sign depend on liquid water content, temperature, and number and size of ice crystals and hail particles. In the EMTM the net amount of charge, $\Delta Q(D, d)$, added per unit time to a graupel particle with diameter $D$, via collisions with ice crystals having diameter $d$ and number concentration $n_{\text {ice }}(d)$ is

$$
\begin{gathered}
\Delta Q(D, d)=n_{\text {ice }}(d) \cdot K_{\mathrm{cc}}(d, D) \cdot\left(1-E_{\mathrm{si}}\right) \cdot \partial Q_{\mathrm{g}}(d, D)+ \\
n_{\text {ice }}(d) \cdot K_{\mathrm{cc}}(d, D) \cdot E_{\mathrm{si}} \cdot Q_{\text {ice }}(d) .
\end{gathered}
$$

Here, $K_{\mathrm{cc}}(d, D)$ is the geometric collision kernel, $\partial Q_{\mathrm{g}}(d, D)$ is the amount of charge transferred per nonsticking collision, $Q_{\text {ice }}(d)$ is the charge on each ice crystal, and $E_{\mathrm{si}}$ is the ice-ice sticking efficiency (set equal to 0.25 ). In Eq. (1), the first term on the right hand side is the amount of charge transferred per unit time to the graupel particle because of rebounding collisions with ice crystals (i.e., noninductive process), while the second term is the amount of charge transferred per unit time because of sticking collisions with ice crystals (i.e., it deals with charge transfer between hydrometeors associated to mass transfer).

As discussed by Solomon (1997), EMTM uses the following expressions for $K_{\mathrm{cc}}(d, D)$ and for $\partial Q_{\mathrm{g}}(d, D)$, respectively, taken from Gillespie (1975) and from Keith and Saunders (1989):

$$
\begin{gathered}
K_{\mathrm{cc}}(d, D)=\pi / 4 \cdot(D+d)^{2} \cdot|\partial V|, \\
\partial Q_{\mathrm{g}}(d, D)=B \cdot d^{a} \cdot|\partial V|^{b} \cdot q(d, D) .
\end{gathered}
$$

Here, $\partial V$ is the difference in the fall velocities of the colliding particles, while $B, a$, and $b$ depend on crystal size and effective liquid water content, and for $q(d, D)$ EMTM uses a functional form based on a parameterization of laboratory experiments supplied by Saunders et al. (1991).

In addition to the charge arising from the noninductive ice-ice collisional mechanism, also the charge accumulation at the cloud boundary (screening layer) is included. Once a 
sufficient amount of charge has been separated to raise the electric field at some point in the cloud to the value necessary for local breakdown, lightning is initiated -i.e., the initiation height is where the electric field exceeds the breakdown field. In this study the breakdown electric field is held constant with height and equal to $200 \mathrm{kV} \mathrm{m}^{-1}$. This value was chosen according to Solomon (1997). In other studies (Marshall et al., 1995a, b) the triggering electric field decreases with increasing altitude, with values approaching $200 \mathrm{kV} \mathrm{m}^{-1}$ at the surface. Then, a routine for plasma propagation is activated at the initiation height. The plasma is modeled as a conductive ellipsoid (representing the intracloud lightning channel in Fig. 1) at the same potential, propagating along the column and collecting charge. While propagation and collection of charge take place, the amount of energy is dispersed by irradiation from the ellipsoid's surface, assumed to be a black body at $20000 \mathrm{~K}$ temperature. The lightning occurs until there is enough energy supplied by the charge to sustain the heat radiative dispersion. For further details on the lightning channel parameterization, please refer to Solomon and Baker (1996).

The specification of the channel length is based on the physical processes that are involved in lightning propagation. In the EMTM, it is assumed that the channel length grows as long as the charge at the head of the channel does not change sign or goes to zero. Specifically, if the channel propagates into a region where the charge induced at the tip goes to zero or switches sign, propagation in that direction is halted. If the lower tip of the channel does not reach the ground (IC lightning), the channel always bears zero net charge. Vice versa, if it reaches the ground, a CG lightning occurs and a net charge flows from the ground to the channel and is evenly distributed along the channel itself, bringing its potential to zero (the potential of the ground). Thus, downward propagation is no longer possible, though the top of the channel may continue upward. At the completion of the parameterized channel, the charge induced on the channel diffuses into the cloud, attaches to hydrometeors and modifies the in-cloud charge profile and electric field.

Each EMTM simulation must be initiated with a vertical atmospheric (temperature and water vapor) profile, which can be taken either from soundings or from numerical weather prediction analysis. This profile provides the basic state of the atmosphere and fills the inner and outer cylinders constituting the model domain. Then, to generate a cloud, a perturbation of the basic state has to be imposed, either by means of a temperature perturbation (thermal bubble) or by a vertical wind at cloud base, or both. The duration of the forcing can be chosen as needed. In the case of a thermal bubble, different thermal perturbation amplitudes ( $\Delta T$ 's) at cloud base can be chosen according to the sounding (Skew-T diagram) for the selected case. An example of this procedure is shown in Fig. 2 for a summer continental profile. From the basic state (black curves) various scenarios of daytime heating from the ground are represented by the three dry adiabatic

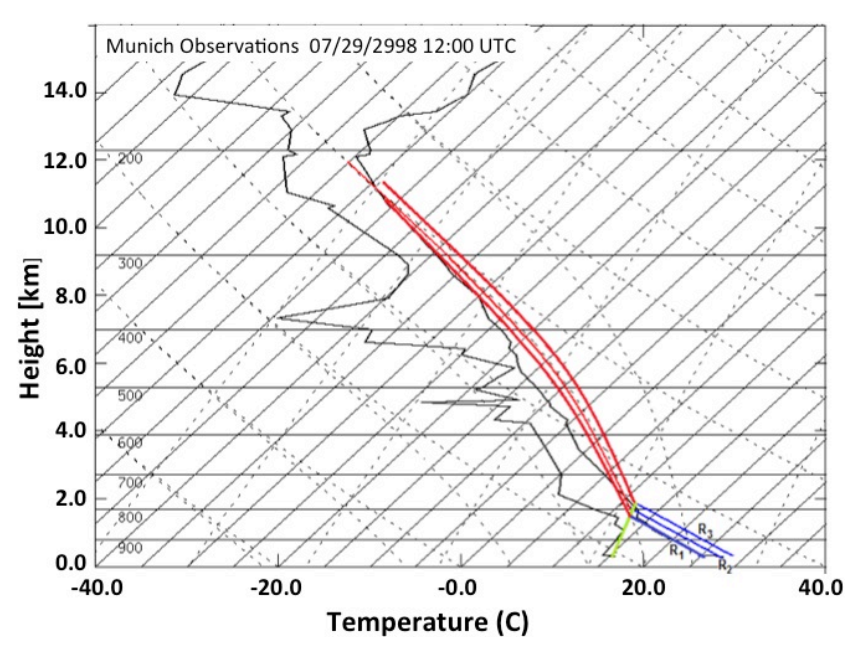

Fig. 2. Skew-T diagram showing how different initialization profiles for the EMTM model can be generated by means of different temperature perturbations below cloud base. The black curves are taken from a continental summer sounding and represent the basic state of the atmosphere. The blue curves (R1, R2, and R3) are three different dry adiabatic thermal perturbations, the green line represents the moisture of the thermal bubble and the three red curves represent the moist adiabatic profiles corresponding to the three different thermal perturbations.

curves that are represented as the blue R1, R2, and R3 lines. These different initial thermal perturbations lead to different initial cloud condensation levels. The thermal bubble is lifted to the condensation level keeping its moisture constant and equal to the moisture at the surface (green line). The conditions at cloud base (i.e., $\Delta T$, saturation conditions, pressure), derived at the intersection of the blue and green lines, change depending on the initial thermal perturbation. They represent the difference of thermodynamic properties (and dynamic properties as well, when vertical wind is also perturbed) between the convective cloud and the environment. Then, for each thermal perturbation, the cloud evolves following the corresponding moist adiabatic (red curves) above the condensation level.

The model requires as input the $\Delta T$ at condensation level (cloud base), the pressure at cloud base, the water vapor mixing ratio, and the vertical wind. Figure 3 shows an example of application of the thermal perturbation described above. The different colors represent the temperature deviation from the basic state due to the evolution of the cloud. Each column represents a time snapshot of the model results. The initial thermal bubble, which is imposed for about $280 \mathrm{~s}$, is shown as the warmer area marked by a circle. In this case the cloud base is at $1000 \mathrm{~m}$. The thermal perturbation extends to the middle troposphere $(5-7 \mathrm{~km})$ during the initial forcing. Then, it rapidly moves upward with simulation time, reaching very high levels (above $10 \mathrm{~km}$ ) after about $400 \mathrm{~s}$. 


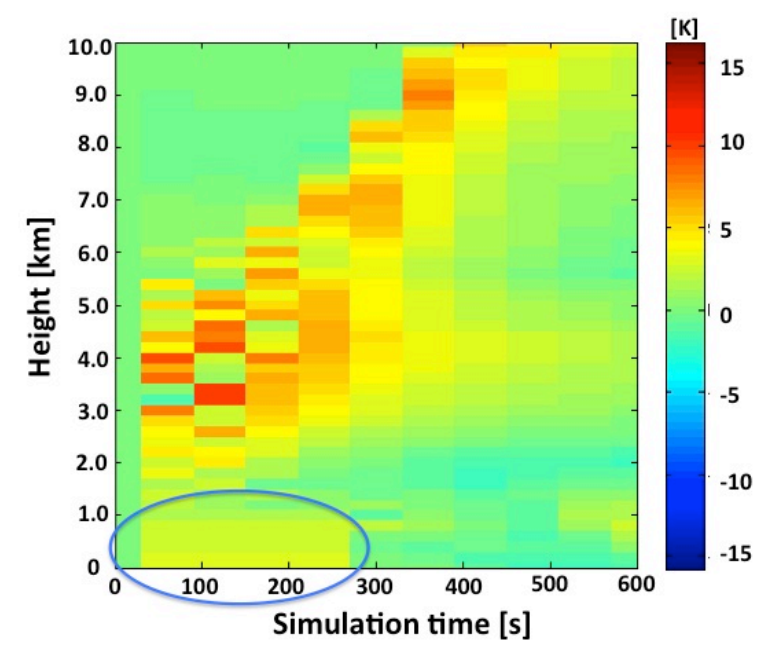

Fig. 3. Temperature perturbation from the basic state for the EMTM model initialization, as a function of model simulation time and altitude. The different colors represent the temperature deviation from the basic state due to the evolution of the cloud.

The characteristics of the cloud produced by the model critically depend on the selected sounding and on type and duration of the initial perturbation. In order to have reliable results it is crucial to choose an initial setup that is physically compatible with the atmospheric environment as represented by the sounding. The output of the model consists of the vertical profiles of various variables in the inner cylinder, as a function of simulation time, that specify both the microphysical and electrical properties of the cloud (i.e., graupel, rain, electric field, lightning discharges) and the thermodynamical state of the atmosphere (i.e., vertical wind, temperature, water vapor mixing ratio). Notably, cases of model instability sometimes occur producing unrealistic results. The most common case happens when the initial perturbation is too energetic. In this case, the model produces excessively strong updrafts and, as a consequence, the residence time of graupel in the $\mathrm{CZ}$ becomes too short. Model instability may also occur when the cloud condensation level is high (around $800 \mathrm{hPa}$ ), as for example in the simulation of continental summer storms characterized by a thick dry layer of absolute instability. Thus, it is necessary to analyze some key output variables (e.g., profiles of temperature and vertical wind) in order to establish if the results are compatible with the meteorological situation of the selected case.

\section{Case studies}

For an in-depth analysis of the EMTM model results, we have selected two case studies, which are characterized by very different synoptic situations and, therefore, by different environmental conditions as clearly represented by the soundings used to initialize the EMTM. The first case study

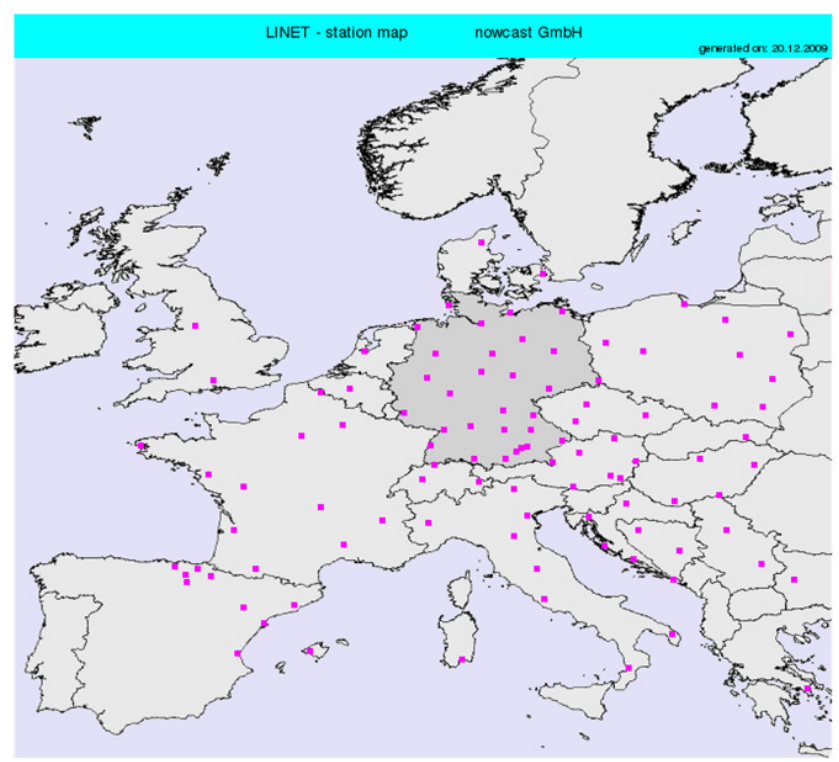

Fig. 4. Distribution of LINET sensors in Europe as of December 2009 .

(Case 1) is a typical summer convective cell that occurred on 29 July 2008 over Munich, southern Germany, triggered by local conditions (strong diurnal warming favoring intense convective activity). During the morning there was an intrusion of dry air in the mid troposphere increasing its conditional instability. In this case, a thick layer of absolute instability characterized the lower atmosphere. The second case study (Case 2) is a disturbance that affected the Lazio region, in Italy, and Rome in particular, producing a very intense hailstorm on 2 July 2009. During the days prior to the event, a cold pool descended from central Europe to the Balkans producing a cyclonic circulation over eastern Europe. Consequently, an eastern flux developed over Italy carrying relatively cold air at mid levels. A cold trough at $850 \mathrm{hPa}$ developed over the Balkans on 29 June, generating, two days later, a strong cold advection over Italy. In addition, the summer solar radiation triggered strong and diffuse convection along the Apennines mountain range. As a result, thunderclouds were carried toward the southwest by upper level winds.

The two case studies were also chosen because of the availability of good lightning data from the LINET network. LINET is a high resolution VLF/LF ground lightning network developed by one of the authors of this paper (HansDieter Betz) at Munich University (Betz et al., 2004, 2007, 2008,2009 ). The network consists now of over 120 sensors in Europe. Figure 4 shows the LINET sensor distribution in Europe as of December 2009, but it has seen a significant expansion in the last $3 \mathrm{yr}$. LINET detects electromagnetic emission from discharges that radiate in the VLF/LF frequency range in the interval $5-200 \mathrm{kHz}$. Pulses with dominant radiation power centered around $10 \mathrm{kHz}$ are typical for both CGs (i.e., classical return strokes) and ICs. One of the most 


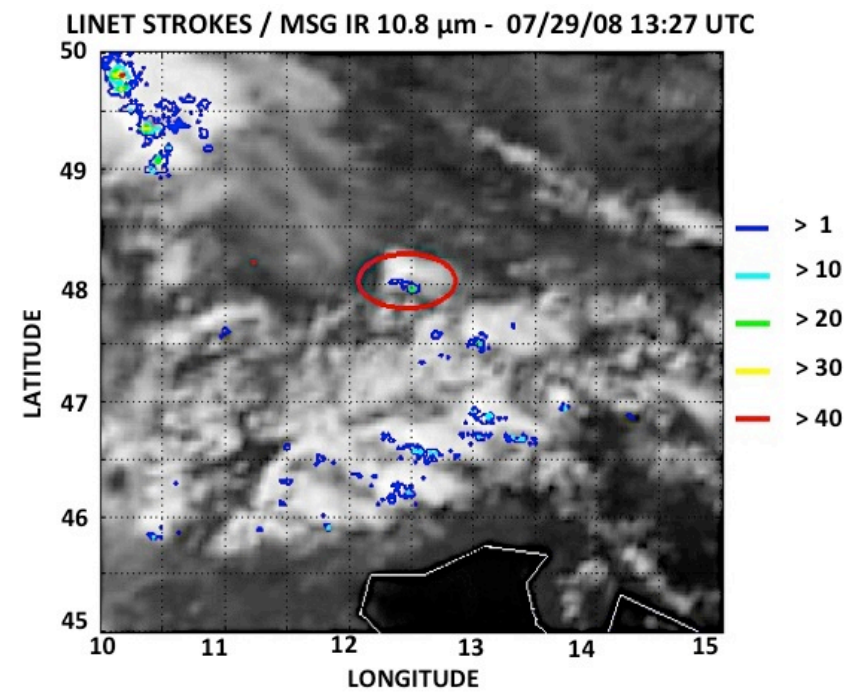

Fig. 5. IR $10.8 \mu \mathrm{m}$ MSG image of a central Europe region at 13:27 UTC, 29 July 2008, with superimposed contours of lightning activity as detected by the LINET network during the previous $15 \mathrm{~min}$. The different colors show the accumulated stroke density over a grid at $2 \times 2 \mathrm{~km}^{2}$ horizontal resolution. The red circle identifies the location of the analyzed thunderstorm cell of Case 1.

important features of the LINET network is the ability to distinguish IC strokes from the CGs following the evolution of a cell from its early stage and, in some cases, to measure the height of the ICs (Betz et al., 2004). LINET has higher efficiency for small-amplitude signals and, thus, locates more IC-strokes than other networks, with a sensitivity threshold around $5 \mathrm{kA}$, depending on the location (Betz et al., 2009). The accuracy for discrimination of ICs and CGs depends on the general 2-D location accuracy in the area - optimal when the network baseline is less than some $200 \mathrm{~km}$, but still guaranteed by the availability of a sensor within $100 \mathrm{~km}$ of a lightning (independent of the network baseline). This condition was satisfied for both case studies, even if, as evidenced in Fig. 4, in the area of Rome the network baseline is much longer than near Munich. Therefore, the distinction ability between ICs and CGs in Rome is the same as in Munich. The detection efficiency, however, was different between Rome and Munich, because of the different sensitivity threshold in the two locations. In Rome, strokes with current greater than $7 \mathrm{kA}$ could be detected, while in Munich the threshold for detection was about $1.5 \mathrm{kA}$. Therefore, for the Munich case, it was possible to detect many weak ICs (with current less than $7 \mathrm{kA}$ ) that in Rome would be undetected. Since small currents are associated mostly to ICs, the detection of CGs is almost the same for Rome and Munich.

LINET lightning data consist of a continuous streaming of records of strokes containing GPS time and geolocation, height and discharge current. Once a time frame of data sampling is selected, a geographical grid at $2 \times 2 \mathrm{~km}^{2}$ resolution is

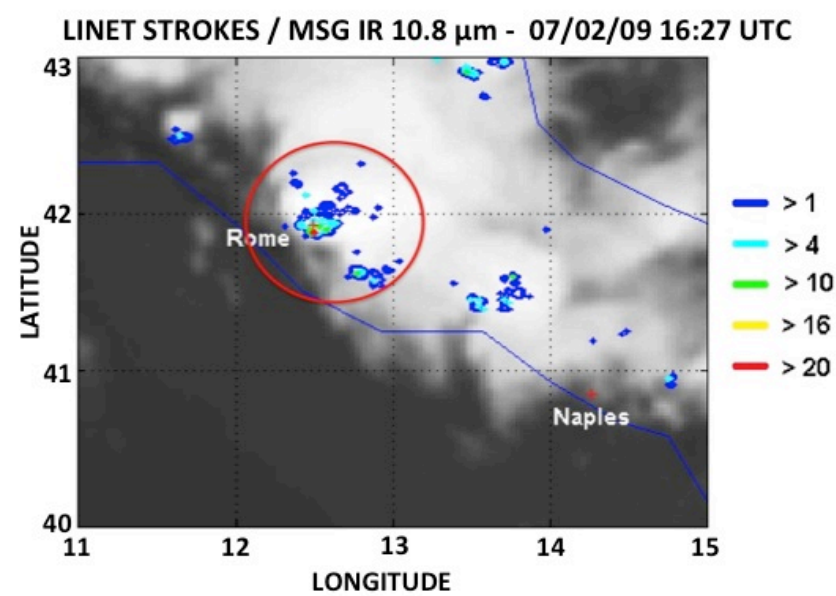

Fig. 6. Same as Fig. 5, but for central Italy at 16:27 UTC, 2 July 2009. The red circle identifies the area selected for Case 2 and the red crosses identify the cities of Rome and Naples.

filled with the cumulated strokes obtaining a matrix of stroke occurrence. Figure 5 shows the storm of Case 1 (Munich) at 13:27 UTC, 29 July 2008, as viewed by the thermal infrared (IR) $10.8 \mu \mathrm{m}$ channel of the Meteosat Second Generation (MSG) geostationary satellite, with superimposed lightning measurements from the LINET network in the previous 15 min (sampled over a $2 \times 2 \mathrm{~km}^{2}$ grid). Here the LINET data reveal the presence of a well-developed single cell, identified by the red circle, over the Munich area with cumulated stroke counts (both CGs and ICs) of between 20 and 30. This isolated cell produced the first stroke at 12:20 UTC and evolved for about two hours producing the last lightning at 14:06. Figure 6 is similar to Fig. 5, but for the storm of Case 2 (Rome) at 16:27 UTC, 2 July 2009. The cell used for this case study, identified by the red circle, reveals a weak activity at the time of the image, with maximum cumulated stroke counts approaching 20 (in the 15 min prior to the MSG image time).

Since 1-D models produce single cells, when comparing the lightning data of real storms with those simulated by a 1-D model, it is necessary to look for real cells as similar as possible to a "synthetic" cell - i.e., to look for convective systems that can be classified as one-cell systems. A single cell is identified where the spatial distribution of the lightning is rather tight and it does not split into secondary cells with time. Examples of how the LINET data are collected for the purpose of this study are given in Figs. 7 and 8, for Case 1 and Case 2, respectively. These figures show the total number of strokes measured by LINET in each $2 \times 2 \mathrm{~km}^{2}$ grid box within a $2 \mathrm{~h}$ time interval (between 12:00 and 13:59 UTC for Case 1, and between 15:00 and 16:59 UTC for Case 2) that corresponds to the duration of each simulation. For Case 1, the maximum cumulated stroke count was 23 , while the total number of strokes registered in one hour was 553. For Case 2, 


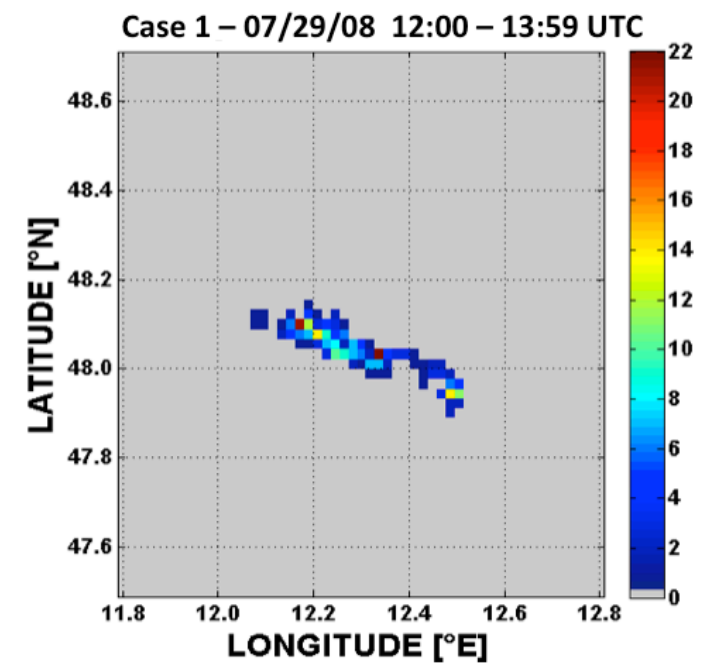

Fig. 7. Cumulated total strokes (IC $+\mathrm{CG}$ ) registered by the LINET network over the Munich area (Case 1) between 12:00 and 13:59 UTC, 29 July 2008. The horizontal resolution is $2 \times 2 \mathrm{~km}^{2}$. The different colors show the total events registered for each pixel.

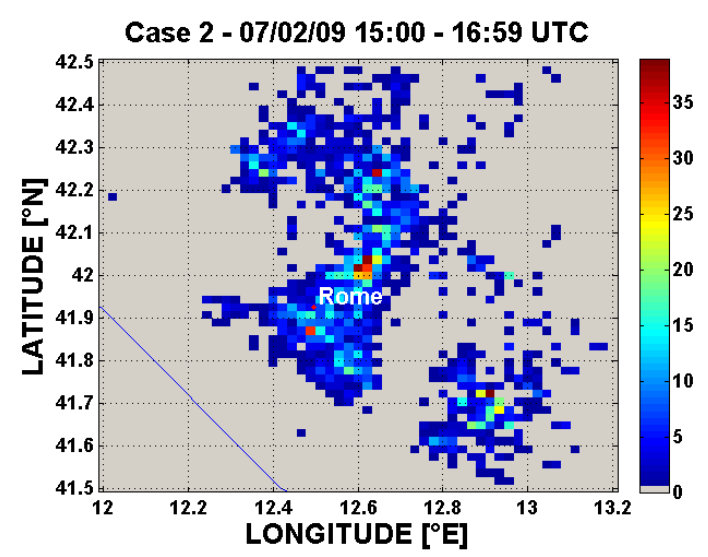

Fig. 8. Same as Fig. 7, but for the Rome area (Case 2) between 15:00 and 16:59 UTC, 2 July 2009.

due to the particular intensity of the event and the good setup of the ground network, the maximum cumulated stroke count among all pixels was as high as 38 in spite of the reduced detection efficiency over the Rome area.

As described in Sect. 2, the EMTM model is initiated with a vertical atmospheric profile of temperature and water vapor that, for each of the present case studies, is taken from a radio sounding close to the corresponding area - red circles in Figs. 5 and 6. Following the methodology illustrated by Fig. 2, atmospheric soundings have been used to create the initial conditions of the simulations for Case 1 and Case 2. In particular, Fig. 2 shows the sounding (temperature and water vapor profiles) over Munich on 29 July 2008 at 12:00 UTC. The initial conditions for cloud initiation in the EMTM Case 1 simulation are given by the blue and

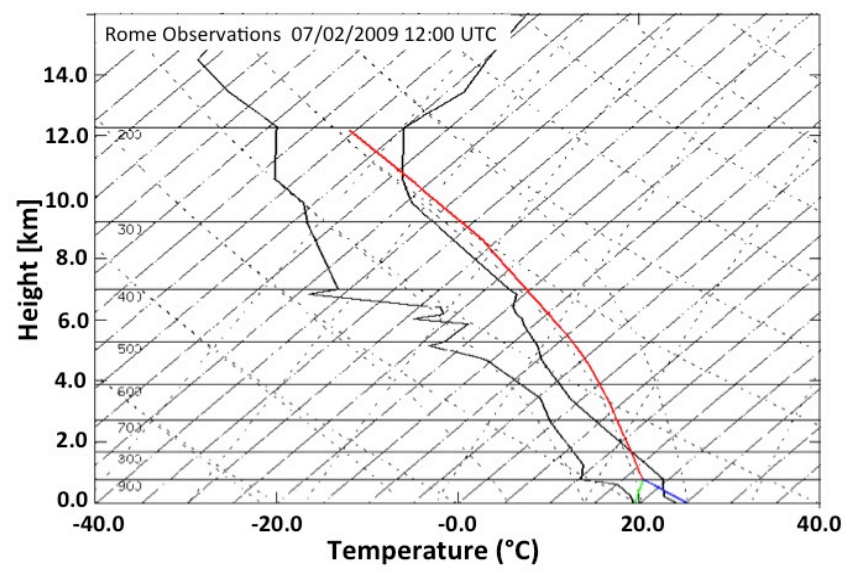

Fig. 9. Radio sounding in Rome on 2 July 2009, 12:00 UTC (black curves), and initial perturbation setup for Case 2. The blue line is the dry adiabatic thermal perturbation, the green line represents the moisture of the thermal bubble, and the red curve is the moist adiabatic profile.

red curves labeled as R2. The (lifting) condensation level resides at $800 \mathrm{hPa}$, which is the starting level for cloud initiation, corresponding to a water vapor mixing ratio of $11 \times 10^{-3} \mathrm{~kg} \mathrm{~kg}^{-1}$ and a temperature of $14^{\circ} \mathrm{C}$ at cloud base. CAPE (convective available potential energy) is $1813 \mathrm{~J} \mathrm{~kg}^{-1}$.

Figure 9 shows the sounding over Rome on 2 July 2009 at 12:00 UTC, as well as the initial conditions for cloud initiation in the EMTM simulation for Case 2. The condensation level resides at $910 \mathrm{hPa}$, with a water vapor mixing ratio of $14 \times 10^{-3} \mathrm{~kg} \mathrm{~kg}^{-1}$ and a temperature of $17.5^{\circ} \mathrm{C}$. CAPE is $2580 \mathrm{~J} \mathrm{~kg}^{-1}$. In this case, the rising parcel is warmer than the environment up to about the $950 \mathrm{hPa}$ level and it acquires kinetic energy. Then, it enters in a stable layer where its temperature becomes lower than the environment. Nevertheless, the parcel has a strong buoyancy contribution due to the moisture carried up in drier environment, and therefore it rises up over the stable layer in spite of a negative $(-2 \mathrm{~K}) \Delta T$ at cloud base. In addition, a vertical wind forcing of $1 \mathrm{~m} \mathrm{~s}^{-1}$ was imposed to simulate the orographic lifting - a value that was estimated from the horizontal wind at the time of the sounding and an average slope of $25 \%$ for the Apennines mountain range. The low cloud base level $(910 \mathrm{hPa})$, due to the moisture carried at lower levels by the sea breeze, causes the formation of a very thick cloud, which is a good environment for charge electrification.

We emphasize the very different initial conditions for EMTM in the two cases, which are particularly evident in terms of the different CAPE and cloud base level. As it will be shown in the next sections, these different initial conditions will lead to very different microphysics and electrical activity in the simulated cells. For both cases, the time extension of the thermal/dynamic perturbation has been set to about $1000 \mathrm{~s}$ with a total simulation time of two hours. The 
duration of the total simulation is quite long with respect to the typical duration of a single-cell storm $(<2 \mathrm{~h}-$ e.g., Byers and Braham, 1949), but we adopted this setup in order to engulf the whole life cycle of the cell, with possible secondary cells.

\section{Modeled lightning activity verification}

Before showing the results of the EMTM simulations for the two selected cases, it is necessary to verify that the EMTM model is a valid tool for simulating cloud electrification. For this purpose, in this section a comparison of the model simulations with lightning data collected by the LINET ground lightning network is carried out. It is worth noting that being the EMTM a one-dimensional model, it would not be possible to compare the time evolution of the simulated and real cells. Therefore, our comparison does not aim at checking the model's ability to quantitatively reproduce the observed lightning activity within a convective cell, but only addresses the consistency in the cloud model results. Specifically, there are two goals: (1) to look for analogies between lightning measurements and the main characteristics of the simulated electrical activity, such as flash rates and time evolution and occurrence of the IC and CG lightning; and (2) to check if the model has a realistic sensitivity to different environmental conditions.

Once the isolated cluster of LINET strokes is detected, as shown in Figs. 7 and 8, a histogram is built using, for each one-minute sampling interval during a $7000 \mathrm{~s}$ time frame, the maximum rate of strokes measured for all $2 \times 2 \mathrm{~km}^{2}$ pixels. We choose to use the maximum rate considering that the 1D model simulates the kinematics and microphysics of the core of the real cell, and that the model results can not be compared to a total flash count or average flash count for the area of the real cell. It is assumed, instead, that by taking the maximum measured rate every minute, the evolution of the core of the real cell is represented in the histogram and, thus, can be better compared to the model results. In addition, one has to consider that especially for the Rome case, the LINET data may be affected by the limited sensitivity of the sensors, which causes some weak strokes to be undetected. Further, while LINET measures strokes, the EMTM simulates the total flash duration in the clouds. Thus, an attempt was made to convert measured strokes into flashes, by grouping strokes that are registered within a given time interval (e.g., $0.2 \mathrm{~s}$ ) and within a given distance (e.g., $2 \mathrm{~km}$ ). The IC and CG histogram curves slightly changed and shifted towards lower values, but the temporal evolution, which is a reliable measure for the storm life cycle, remained the same as it was for the strokes. Thus, being aware that there is no absolute criterion to convert strokes into flashes, for the purpose of this paper we decided to use LINET strokes.
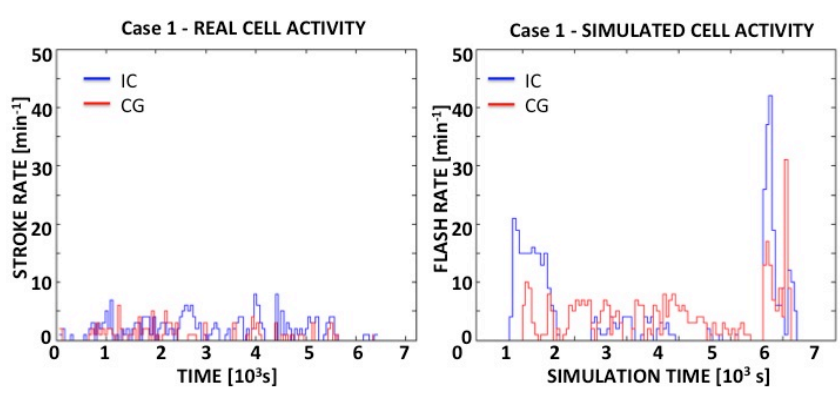

Fig. 10. Comparison between lightning measurements (left panel) and model results (right panel) for Case 1 (Munich, 29 July 2008). The left-panel histograms are built using the maximum number of IC and CG strokes that are registered in one-minute sampling intervals during a time frame of $7000 \mathrm{~s}$ for all pixels in the area circled in Fig. 4. The right-panel histograms show the IC and CG flashes produced by the EMTM model in one-minute sampling intervals during the $7000 \mathrm{~s}$ simulation time. In both panels, red line is for CG and blue line is for IC.

The left panel in Fig. 10 shows the histograms obtained, both for IC and CG strokes, from the LINET measurements relative to the cell highlighted by the red circle in Fig. 5 (Case 1), along the whole life cycle of the cell itself. As a comparison, the right panel shows the corresponding histograms for the EMTM-simulated IC and CG flash rates (in one-minute sampling intervals) vs. the simulation time. Both the real and the simulated lightning activity show a weak cell with a flash rate (or stroke rate), which does not show significant variation with time, except for the peaks at the initial and final stages of the simulation, which are not present in the real data. For this case study the cloud model has the tendency to produce larger $\mathrm{CG}$ rates than observed, while the rate values for IC lightning are close to the observation, except for the initial and final stages. As it will be shown in the next section, the electrical stress at low levels at the initial and final times of the simulation derives from the rain and graupel fields. However, in understanding the origin of the discrepancies it is important to take into account the limitations intrinsic to a 1-D model. A characteristic of the selected continental summer event (Case 1) is an elevated condensation level due to the presence of a relatively dry atmosphere at low levels. In this type of atmospheric condition the EMTM model has more difficulties to simulate a plausible electrical activity due the inadequate parameterization of the entrainment. In essence, the model tends to produce stronger vertical motions than in nature (therefore, higher supersaturation and latent heat release leading to a deeper cloud) mainly because of the entrainment parameterization, which cannot reproduce adequately the loss of energy by the warm bubble due to mixing with surrounding dry air. Indeed, the 1-D representation of the dynamics does not allow for a good description of the mixing occurring in real clouds due to turbulence or to vertical wind shear. This has a negative impact 

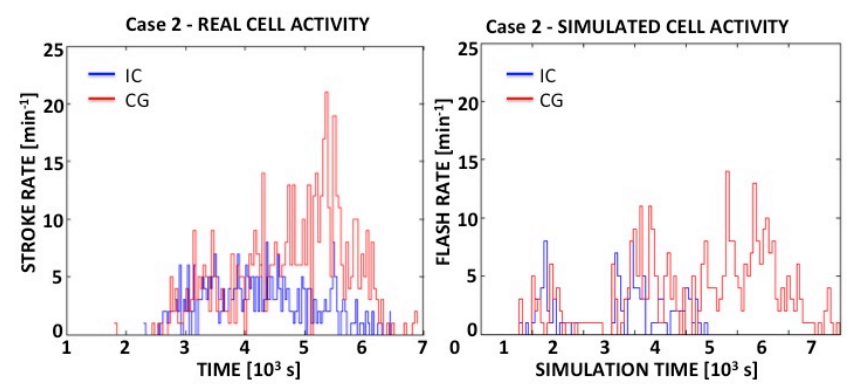

Fig. 11. Same as Fig. 10, but for Case 2 (Rome, 2 July 2009).

on the cloud microphysics, and hence on the electrical activity, in spite of the detailed explicit microphysics scheme that characterizes the model.

The analogous results for Case 2 are shown in Fig. 11. As for Fig. 10, the left panel shows the registered activity, while the right panel shows the EMTM results. The measurements reveal the presence of significant IC activity throughout the storm, and increasing CG activity during its evolution, particularly intense during the central phase of the event. Due to the high sensitivity threshold (7 kA) of the LINET network in Rome at the time of the event, the IC activity shown in the left panel might be underestimated. The time evolution of CG activity (approximately within the same time frame in the simulation as in the observations), as well as the order of magnitude of the flash rates, is represented quite well by the model (please note that when grouped into flashes as explained above, the LINET maximum stroke rate drops from 21 to 14). Also, the IC activity shows some similarities: it is less intense than the CG activity and it starts at the early phase of the cell evolution, but, while the measurements reveal IC activity throughout the evolution of the cell, in the model the ICs cease as the CGs intensify. This behavior will be explained in the next section, where the model results will be discussed in detail and the relationships between electrical activity and microphysics will be analyzed. However, it is worth mentioning here that the time evolution of the simulated IC flash rate is affected by the fact that a constant breakdown electric field has been used (see Sect. 2), while the CG flash rates are more reliable since they result from the most intense lightning discharges.

From these results it can be concluded that the EMTM properly responds to the different environmental conditions of the two selected cases, producing very different electrical activity, and, most important, that some of the differences between the two cases are evidenced also in the measured activity. However, it must be also stressed that the measured data show some features that are not simulated well in the model (such as the IC time evolution in Case 2, and the overestimation of ICs at the early and final stages of Case 1). This aspect, which is mostly due to the intrinsic limitations of a 1D framework, should be taken into account when the EMTM model is used as a tool for studying cloud electrification processes, as it will be shown in the next section. Finally, it is worth mentioning that the use of lightning location/detection systems with varying performances in different locations (as it is for LINET, which has different sensitivity thresholds in Munich and in Rome) makes it very difficult to perform extensive validations of cloud electrification models. The characteristics of the available data (i.e., IC vs. CG discrimination ability, detection efficiency, accuracy of location) should be always taken into account.

\section{Results}

In this section the microphysical and electrical output from the EMTM model is thoroughly analyzed. First, the results of the simulations for the two selected case studies are illustrated. Then, the results of sensitivity studies on the initial setup of the model are discussed and quantitative relationships between the cloud dynamical and microphysical properties and the electrical activity are derived.

\subsection{Analysis of simulated clouds}

Figure 12 shows the results for the case study of 29 July 2008 over Munich (Case 1). Each panel shows the temporal evolution during the simulation of: the hydrometeor mixing ratios $\left(\mathrm{kg} \mathrm{kg}^{-1}\right)$ (graupel, ice, cloud water, and rain, respectively in panels I-IV); the lightning occurrences (in panel I), where IC's initiation height is shown as red crosses and CG occurrences are represented as green crosses; the vertical wind (in panel V); and the charge density (in panel VI). Results are shown as a function of simulation time and altitude. The blank area in the blue rectangle is the effect of the model initialization described in Sect. 2. The development of free convection starts immediately during the forcing and the cloud produces a high amount of graupel (panel I), reaching mixing ratios of about $8 \times 10^{-3} \mathrm{~kg} \mathrm{~kg}^{-1}$ after $1200 \mathrm{~s}$ of simulation time. The updraft, in this first phase, reaches the maximum value of $25.2 \mathrm{~m} \mathrm{~s}^{-1}, 1000 \mathrm{~s}$ before the first peak of concentration of graupel is reached. Panel I shows that the first stroke occurs at $766 \mathrm{~s}$ and that it is an IC event, consistent with what is typically observed (Krehbiel, 1981; MacGorman and Nielsen, 1991), while the first CG stroke is generated at $982 \mathrm{~s}$. At the same time, panel VI shows the presence of a high charge density area, marked as A, which corresponds to a high rate of charge separation and, therefore, to intense IC activity (red crosses in panel I) in the cloud. The high charge density gradient is necessary to overcome the breakdown electric field, but it occurs below the height where the graupel mixing ratio is at its maximum, in the region where graupel is growing by riming, and where the ice crystals are present (with lower concentration than at high altitudes $[t \sim 800 \mathrm{~s}$, $H \sim 10000 \mathrm{~m}])$. The electrification and, hence, lightning is associated with the region of particle interactions. The high 


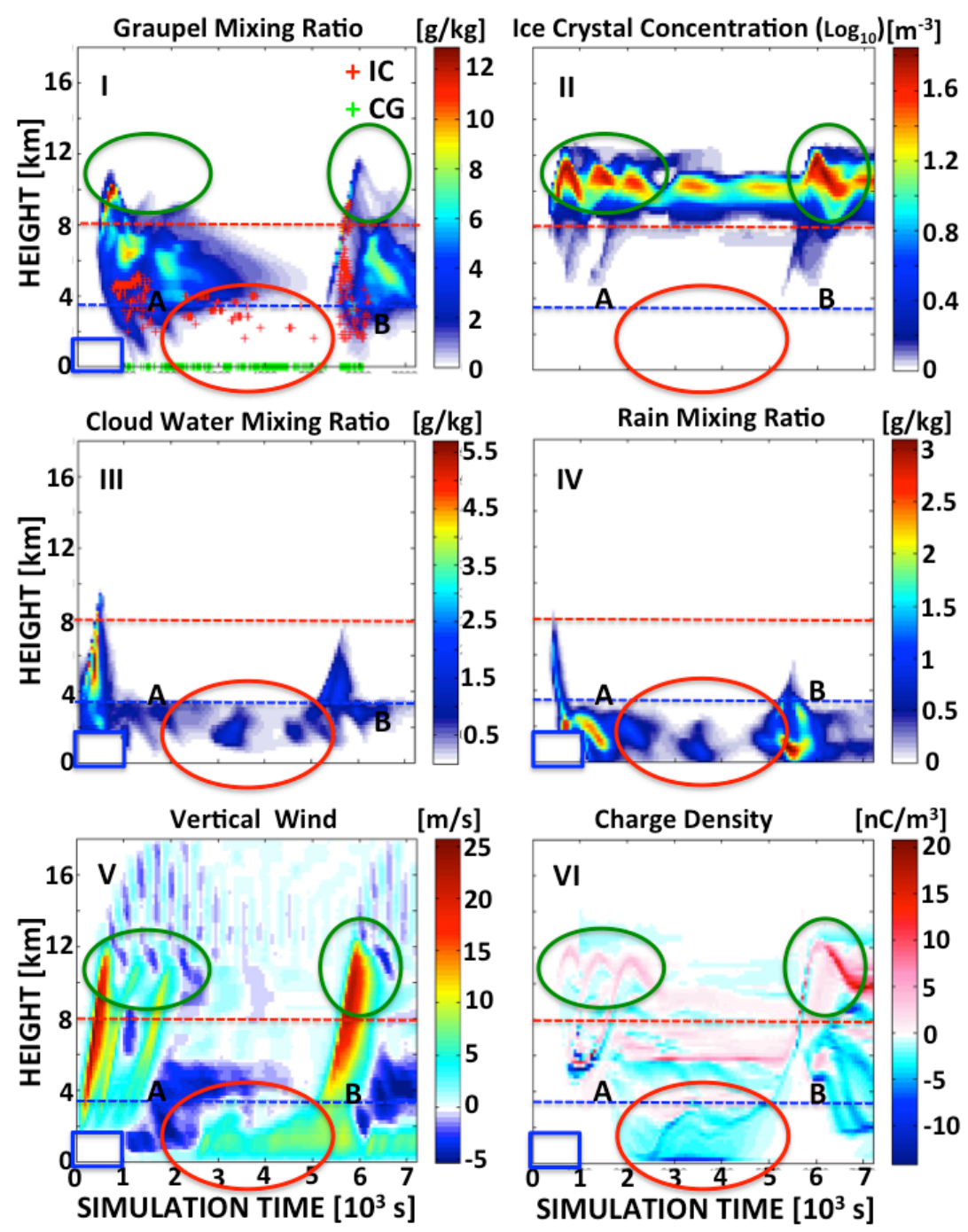

Fig. 12. Temporal evolution of hydrometeor mixing ratios $\left(\mathrm{g} \mathrm{kg}^{-1}\right)$, lightning occurrences, vertical wind $\left(\mathrm{m} \mathrm{s}^{-1}\right)$ and charge density $\left(\mathrm{nC} \mathrm{m}^{-3}\right.$ ) for Case 1 (Munich, 29 July 2008). The panels show: (I) graupel mixing ratio and lightning, (II) ice crystals concentration expressed in a $\log _{10}$ scale, (III) cloud water mixing ratio, (IV) rain mixing ratio, (V) vertical wind, and (VI) charge density. Results are shown as a function of simulation time and height. The dotted red and blue lines mark the charging zone (CZ in the text). In panel (I) the IC are red crosses at the height where they initiate, and the CG are green crosses (shown at the surface). Each column represents a time step of $60 \mathrm{~s}$. The red circle evidences a phase of negative charge density at low levels (see text). The green circles highlight the presence of high concentration of ice crystals at high levels associated to high positive charge density. Letters A and B evidence the phases of intense IC activity. The blue rectangle evidences the cloud initiation phase.

altitude of supercooled droplets (panel III) is a testament to the vigorous updraft, which strongly influences the graupel production/particle interactions in the $\mathrm{CZ}$, identified as the region where the noninductive electrification processes occur (Takahashi, 1978; Jayaratne et al., 1983; Baker et al., 1987).

The coexistence of supercooled cloud droplets with ice crystals at high altitudes (due to the strong updraft as shown in panel V), and the presence of high number density of graupel are the key factors for the ice-graupel noninductive charging process represented in the EMTM model, as described by Nelson and Baker (2003). The surface charge separation of the ice crystals during growth is ensured by the presence of supercooled droplets, carried to high altitudes because of the strong updraft. The negative charge on the ice crystal surface is transferred by impact to a colliding graupel pellet. The graupel starts to fall down immediately after its formation, carrying negative charge to lower levels in the cloud and melting into rain further down. In this phase, the CG lightning activity becomes predominant and the presence of a negative charge density, even at low levels (red circle in panel VI), assures the continuity of electrical activity throughout the life cycle of the thunderstorm cell. 
Because of the continuation of this weak lightning activity (evidenced by the red circle in panel I) we consider this cell as a unique case with two distinct phases. The first phase, between time 1000 and $2000 \mathrm{~s}$, is characterized by strong downdrafts developed in the cloud due to rain evaporation. This process was well described by early cloud models (Klemp and Wilhelmson, 1978) as responsible for the development of gust fronts and, under favorable wind shear environment, for the continuous development of new cells. The second phase is depicted as B. Here the graupel mixing ratio evolution between $5200 \mathrm{~s}$ and $6500 \mathrm{~s}$ is illustrated. At about $5000 \mathrm{~s}$, the convection starts again, with strong updrafts and production of high concentration of the hydrometeors. It is worth noting, as for the first phase described above, the presence of supercooled droplets carried to higher altitudes, associated with strong IC activity. The graupel at first is carried upward with the ice particles and then, as it grows, starts descending leading to a strong charge separation. As a consequence, the model reproduces an increase of lightning activity. The strong charge separation process corresponds to relatively high concentrations of ice crystals in the $\mathrm{CZ}$, represented by the tail shown in panel II.

The green circles in panels II and VI highlight evolution phases where high density positive charge at high altitudes (10-12 km) follows the evolution of high ice crystal concentration (panel II). These phases are characterized by the presence of positive dipole (positive upper, negative lower) with upper IC flashes. These results confirm the simulations from Mansell et al. (2010) and the polarimetric radar analysis by Bruning et al. (2007) where upper level IC lightning was associated to the development of a significant upper level positive charge region. The central phase of the cell evolution is characterized by the presence of a classic tripole structure (positive-negative-positive) within the CZ, with a smaller lower positive charge region, produced by noninductive charge separation between graupel and small ice particles. During this phase, when the updraft is weak or absent, and no riming growth process is expected (no liquid water is present at high levels), other charging conditions occur, such as supersaturation with respect to ice (as suggested by Mansell et al., 2010), considered a sufficient condition for charge separation. The charge density separation in this region ensures the presence of lower altitude IC and CG lightning.

Figure 13 shows the results obtained for the case study of 2 July 2009 over Rome (Case 2). A strong updraft is present within the $\mathrm{CZ}$ carrying supercooled cloud droplets to high altitudes during the initial phase of cloud formation, followed, at about $600 \mathrm{~s}$ simulation time, by the formation of graupel in the $\mathrm{CZ}$, and by growing ice crystals above the CZ. As in the previous case, the first stroke is an IC and it occurs after $732 \mathrm{~s}$ of simulation time. It is followed by two IC flashes and finally by the first CG flash at 772 s, when graupel pellets fall to lower altitudes within the cloud. After the first updraft, at about $1000 \mathrm{~s}$ a strong downdraft develops caused by precipitation (panel IV), inhibiting the formation of graupel and confining the cloud droplets below the CZ. Then, a new phase starts at about $2000 \mathrm{~s}$ with very strong updraft (larger green circle in panel V), carrying supercooled cloud droplets to higher levels, sustaining the growth of ice crystals (panel II) and the formation and growth of graupel particles (panel I). The result is a strong charge separation in the $\mathrm{CZ}$ (panel VI), positive at the upper levels and negative at the lower levels, propagating above the $\mathrm{CZ}$ due to the presence of growing ice crystals and below the $\mathrm{CZ}$ because of falling graupel pellets (red arrows in panel VI). The effect is the resumption of the IC electrical activity at 2700 s simulation time (see also Fig. 11, right panel) with a considerably higher altitude of the initiation point of the IC (green arrow in panel I) and intense IC activity within the CZ, strongly related to the presence of graupel. As seen for Case 1, the CG activity lasts throughout the duration of the simulation, sustained by the high negative charge density at low levels particularly between $4000 \mathrm{~s}$ and $7200 \mathrm{~s}$ of simulation time. For this reason, the simulation can be seen as representative of one single cell experiencing two different intensification phases.

The model tends to underestimate the IC activity in both cases (Munich and Rome) except at the initial and final stages in Case 1. This is due mainly to the assumption that the constant breakdown electric field does not change with height, as opposed to numerous studies where the triggering electric field decreases with height (as in Marshall et al., 1995a, b). For Case 2, another factor that could affect the IC lightning activity is the large amount of CG lightning simulated by the model after about 3000 s. Panel I in Fig. 13 shows this strong CG activity in the second half of the cell's life cycle. As mentioned before, this activity is due to the presence of negative charge at low level, marked by the red arrows in panel VI. We have to point out that the CG lightning is constituted by a channel that propagates vertically, reaching the ground and depleting charge from the cloud. The charge depletion by a strong CG activity can inhibit the IC triggering in the model.

Another consequence of the constant electric field assumption is the low initiation height of some of the ICs in the CZ, as shown in panels I of Figs. 12 and 13. Both from VHF observations (Rison et al., 1999; Wiens et al., 2005; Bruning et al., 2007) of lightning discharges and from modeling studies (Kuhlman et al., 2006; Fierro et al., 2006; Mansell et al., 2010; Barthe et al., 2012), flashes are usually triggered above $5 \mathrm{~km}$ altitude. The low level (below $5 \mathrm{~km}$ ) IC triggering in our results is due to the charge density distribution in the simulated cloud in relation to the value of the constant breakdown electric field assumed in the model. In Fig. 12, for example, high charge density and gradient at $1000 \mathrm{~s}$ of simulation time causes the high IC rate at about 4-5 km altitude (evidenced as A in panel I). Also, in Fig. 13, the initiation of ICs in the $\mathrm{CZ}$ around $5 \mathrm{~km}$ or below is associated to high charge density with a tripole structure in the $\mathrm{CZ}$ (positive, negative, positive). It is worth noting, however, that the analysis of the 

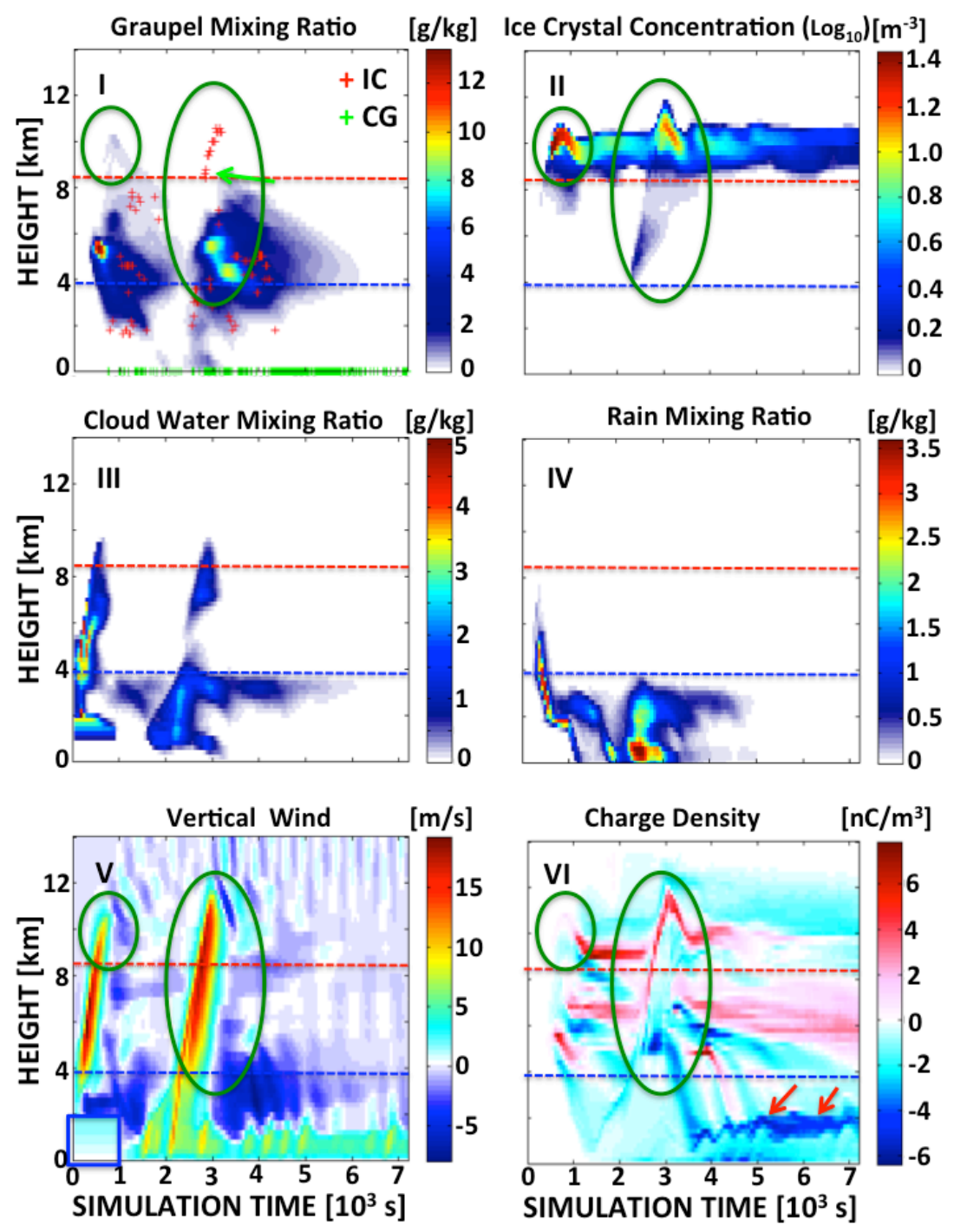

Fig. 13. Same as for Fig. 12, but for Case 2 (Rome, 2 July 2009). The green circles evidence the presence of growing ice crystals and high concentration of ice crystals at high levels associated and high positive charge density. The red arrows in panel (VI) indicate high negative charge density at low levels. The green arrow in panel (I) indicates a very high initiation height of IC's. The blue rectangle evidences the cloud initiation phase, where, besides the thermal perturbation, a constant vertical wind at cloud base has been applied to simulate orographic lifting.

height of the LINET strokes for the two selected case studies reveal the presence of a large number of strokes below $5 \mathrm{~km}$ for the Rome case, while, for the Munich case, strokes are confined above $5 \mathrm{~km}$. The ICs below $5 \mathrm{~km}$ (or even around $2 \mathrm{~km}$ ) can be the result of unsuccessful CG flashes that manage to find opposite charged regions in the cloud instead of the ground.

The results shown above confirm that graupel plays a key role in cloud electrification processes, as shown by several modeling and observational studies (e.g., McCaul et al., 2009; Wiens et al., 2005; Kuhlman et al., 2006; Deierling et al., 2008). Cecil et al. (2005) show that as radar reflectivity (and, by inference, graupel) increases aloft (above $40 \mathrm{dBz}$ ), the total flash rate increases as well. In particular, the IC activity in the $\mathrm{CZ}$ is strongly correlated with the graupel mixing ratio, and the highest occurrence rate of IC flashes is found in correspondence with strong updrafts. The updraft supplies moisture and supercooled droplets along the cloud column and it also sustains the graupel particles in the CZ, ensuring their role in effective charge separation following noninductive process, as demonstrated by several laboratory studies such as Takahashi (1978) and Saunders et al. (1991). However, the EMTM shows that the presence of supercooled droplets at high levels, ensuring the growth of ice crystals with net charge separation on their surface, is another important factor leading to the presence of IC activity at high 
altitudes above the $\mathrm{CZ}$ where graupel is not present. The $\mathrm{CG}$ activity is strongly related to the presence of negative charge at lower levels (within and below the $\mathrm{CZ}$ ) carried by precipitating hydrometeors.

\subsection{Quantitative relationships between cloud microphysics and lightning activity}

From the previous results it is evident how the EMTM model can help in understanding the mechanism of cloud electrification following the noninductive ice-ice process. Using experimental results on ice electrification in conjunction with the EMTM it would be possible to investigate the correlations between cloud dynamics, microphysics and electrical activity. While some conceptual aspects about cloud electrification are qualitatively understood, EMTM can be used to find quantitative correlations between the electrical activity of thunderstorms and their microphysical characteristics in order to build a systematic criterion for cloud classification based on their electrical properties. As we stated in the introduction, this cloud model can resolve explicitly the microphysics of the cloud while, usually, 3-D cloud resolving models use bulk microphysics. Moreover, by individually predicting the IC rate and CG rate it is possible to understand how well the model captures the co-evolving kinematic, microphysical, and electrical properties, and agrees (or not) with observations. By predicting total lightning, and by using bulk microphysics, it would not be possible to gain such useful insights about cloud microphysics and its electrical properties.

However, strong variability from one case to another has been found, showing that the model results depend critically not only on the environmental conditions, but also on the initial perturbation that is used to initiate the cloud simulation. This is evidenced by some sensitivity studies that we have carried out for different cases, using different initial conditions. In particular, the results of a sensitivity study on the initialization parameters for the 2 July 2009 case are illustrated below. Specifically, the EMTM initial perturbation parameters have been changed (Case 2A) with respect to the control run (Case 2) as indicated in Table 1, which also provides some of the results of this sensitivity test. In Case 2, a weak vertical motion induced by the orographic forcing and a thermal deviation from the basic state at cloud base $\Delta T=-2 \mathrm{~K}$ are assumed. Case $2 \mathrm{~A}$ represents a storm that has less energy than Case 2 (i.e., lower CAPE and CAPE in the CZ as derived from the initial conditions), since the initial perturbation $\Delta T=-2.3 \mathrm{~K}$ generates a cloud that is characterized by lower humidity and higher (and colder) cloud base. As a result, the total number of lightnings, both IC and CG, are very significantly reduced in Case $2 \mathrm{~A}$. However, the IC/CG ratio for both simulations evidences some problems already mentioned in the previous section that could be attributed to the inability of the model to trigger correctly the ICs because of the constant breakdown electric field assumption. Note that both model configurations for cloud initialization
Table 1. Comparison of EMTM configuration and results for the sensitivity test for Case 2 (Rome, 2 July 2009). The following parameters are considered: cloud base level (i.e., the condensation level of the initial cloud); $\Delta T$ (i.e., the thermal disturbance with respect to the environment of the initial cloud); mixing ratio (i.e., the mixing ratio of the parcel at ground level, assuming that the displacement is dry adiabatic); vertical forcing (i.e., the imposed initial updraft); total time (i.e., the total duration of the simulation); forcing duration (i.e., the time extension of the forcing); CAPE (i.e., the Convective Available Potential Energy); CAPE C-Z (i.e., the CAPE calculated between $0{ }^{\circ} \mathrm{C}$ and $-25^{\circ} \mathrm{C}$ levels); IC (i.e., the total amount of simulated intracloud lightning); $\mathrm{CG}$ (i.e., the total amount of simulated cloud-to-ground lightning).

\begin{tabular}{lrr}
\hline & Case 2 & Case 2A \\
\hline Cloud base level (hPa) & 910.0 & 860.0 \\
$\Delta T(\mathrm{~K})$ & -2.0 & -2.3 \\
Mixing ratio $\left(\mathrm{g} \mathrm{kg}^{-1}\right)$ & 14.0 & 12.0 \\
Vertical forcing $\left(\mathrm{m} \mathrm{s}^{-1}\right)$ & 1.0 & 1.0 \\
Total time $(\mathrm{s})$ & 7200.0 & 7200.0 \\
Forcing duration $(\mathrm{s})$ & 1000.0 & 1000.0 \\
CAPE $\left(\mathrm{J} \mathrm{Kg}^{-1}\right)$ & 2580.0 & 1105.0 \\
CAPE C-Z $\left(\mathrm{J} \mathrm{Kg}^{-1}\right)$ & 1580.0 & 900.0 \\
$\mathrm{IC}$ & 105 & 41 \\
$\mathrm{CG}$ & 365 & 5 \\
\hline
\end{tabular}

are compatible with the meteorological conditions of the selected case - as demonstrated by the fact that both show plausible temperature and vertical wind profiles, thus, representing different possible real cells compatible with these environmental conditions.

Figure 14 shows the evolution of the simulated electrical activity for the two cases of this sensitivity test in terms of IC and CG histograms similar to those of Figs. 10 and 11, as well as of the IC initiation altitudes. As compared to the control run, which shows an intense CG activity throughout the whole evolution of the cell, the electrical activity in Case 2A is much weaker (about two orders of magnitude for the CGs) and limited to the early stages of cloud evolution. In addition, it is mainly due to IC flashes; and finally these latter, contrary to Case 2, never initiate above the CZ. Not surprisingly, also the microphysics shows significant differences between the two cases. Figure 15 shows the temporal evolution of graupel and rain mixing ratios for Case 2 and Case $2 \mathrm{~A}$. As compared to the control run, Case $2 \mathrm{~A}$ shows relatively small amounts of rain and graupel, while the cell development is confined within the first $2000 \mathrm{~s}$ and no second phase is evident - thus, confirming the lightning results of previous Fig. 14. Noteworthy, comparison with the LINET measurements available for this event (shown in the left panel of Fig. 11) shows that the time evolution of the electrical activity of the cell is much better reproduced in Case 2 than in the Case $2 \mathrm{~A}$ - which is the reason why Case 2 has been taken as the reference simulation. 


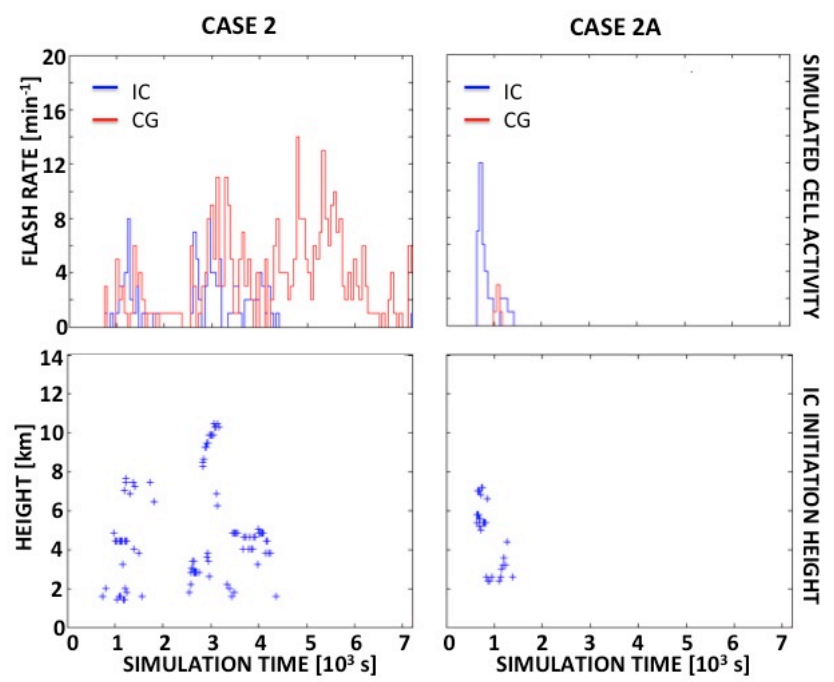

Fig. 14. Comparison between the evolution of the simulated lightning activity for Case 2 (left column) and Case 2A (right column). The top panels, showing the IC (red line) and CG (blue line) flashes produced by the EMTM in one-minute sampling intervals during the $7000 \mathrm{~s}$ simulation time, have been built as described in Sect. 4 also note that the histograms for the control run (Case 2) have been already shown in Fig. 11 and are duplicated here for convenience. The bottom panels show the evolution of the IC initiation heights.

This type of sensitivity studies were also performed for Case 1 , confirming a high sensitivity of the results to the initial conditions that in principle can be chosen quite arbitrarily for any given sounding. This induced us to consider more cases, and different initial perturbations, in order to look for statistical correlations between microphysics and lightning. Specifically, besides the two cases already described in the previous sections (Munich, 29 July 2008 and Rome, 2 July 2009), two additional cases were selected: one is the Wadi Ara (Israel) case of 6 April 2006, and the other is a second event over Munich that took place on 11 July 2008. The first event was a maritime storm that developed within a cyclonic system centered over Israel, with a cold pool in the middle troposphere positioned in the eastern Mediterranean. The second event was characterized by a weak southwesterly flow driven by a large depression centered over the North Sea.

For each of the four cases several simulations, corresponding to different initial conditions, were performed - for a total of 16 simulations. Each simulation lasted 7200 s, and the output was collected every minute. After a detailed analysis on the consistency and variability of the simulated cloud electrification properties with respect to its microphysical structure and to the initial conditions, a database of simulated microphysical and thermodynamical cloud profiles and associated lightning activity was generated. This database was then used in our search for statistical correlations between the

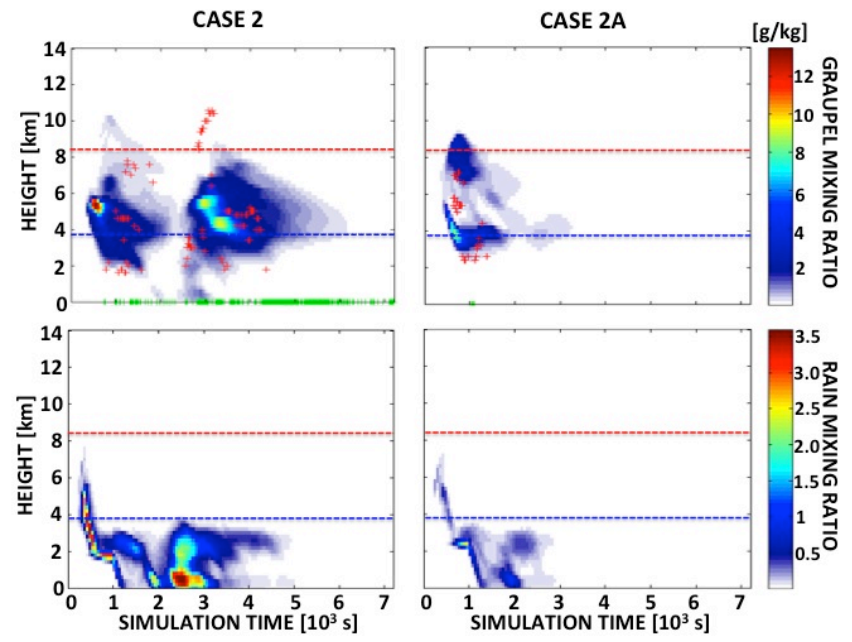

Fig. 15. Comparison between the evolution of the simulated graupel mixing ratio and lightning activity (top panels) and rain mixing ratio (bottom panels) for Case 2 (left column) and Case 2A (right column). The charging zone is delimited by the dotted red and blue horizontal lines. In top panels the ICs are marked as red crosses at the height where they initiate, and the CGs as green crosses at the surface. Finally, note that the results for the control run (Case 2) have been already shown in Fig. 13 and are duplicated here for convenience.

microphysical/thermodynamical properties of a cloud and its electrical activity.

Our analysis in Sect. 5.1 clearly shows that the electrical activity is mostly correlated with graupel and vertical motions - and therefore with the presence of supercooled cloud droplets at high levels and growing ice crystals. Thus, we have focused our study on the relationships of graupel columnar ice water content $\left(\mathrm{CIWC}_{\mathrm{g}}\right)$ and vertical wind at the bottom of the $\mathrm{CZ}\left(w_{\mathrm{CZ}}\right)$ with total $(\mathrm{IC}+\mathrm{CG})$ flash rate produced by the cloud - with all variables sampled over one minute. The results are shown in Fig. 16 as scatterplots of CIWC $_{\mathrm{g}}\left(\mathrm{kg} \mathrm{m}^{-2}\right)$ and $w_{\mathrm{CZ}}\left(\mathrm{m} \mathrm{s}^{-1}\right)$ vs. the total flash rate. Evidently, there is only a semi-quadrant covered by the graupellightning data, meaning that the high flash-rate values are incompatible with low values of graupel content. More specifically, according to the EMTM simulations, to each sampled total flash rate corresponds a minimum threshold of $\mathrm{CIWC}_{\mathrm{g}}$ in the cloud that increases with increasing flash rate. As a result, it has been possible to find a best fit (red line in Fig. 16) representing a linear relationship of the threshold between the total flash rate and the minimum value allowed for columnar graupel. As in the case of graupel, the vertical motion/lightning data fall in one semi-quadrant, suggesting that there exists a minimum value of $w_{\mathrm{CZ}}$ that allows a given total flash rate. This is reasonable because the updraft present at the bottom of the $\mathrm{CZ}$ supplies moisture and supercooled droplets along the cloud column and, as it propagates upward, it also sustains the graupel particles within the $\mathrm{CZ}$, thus 

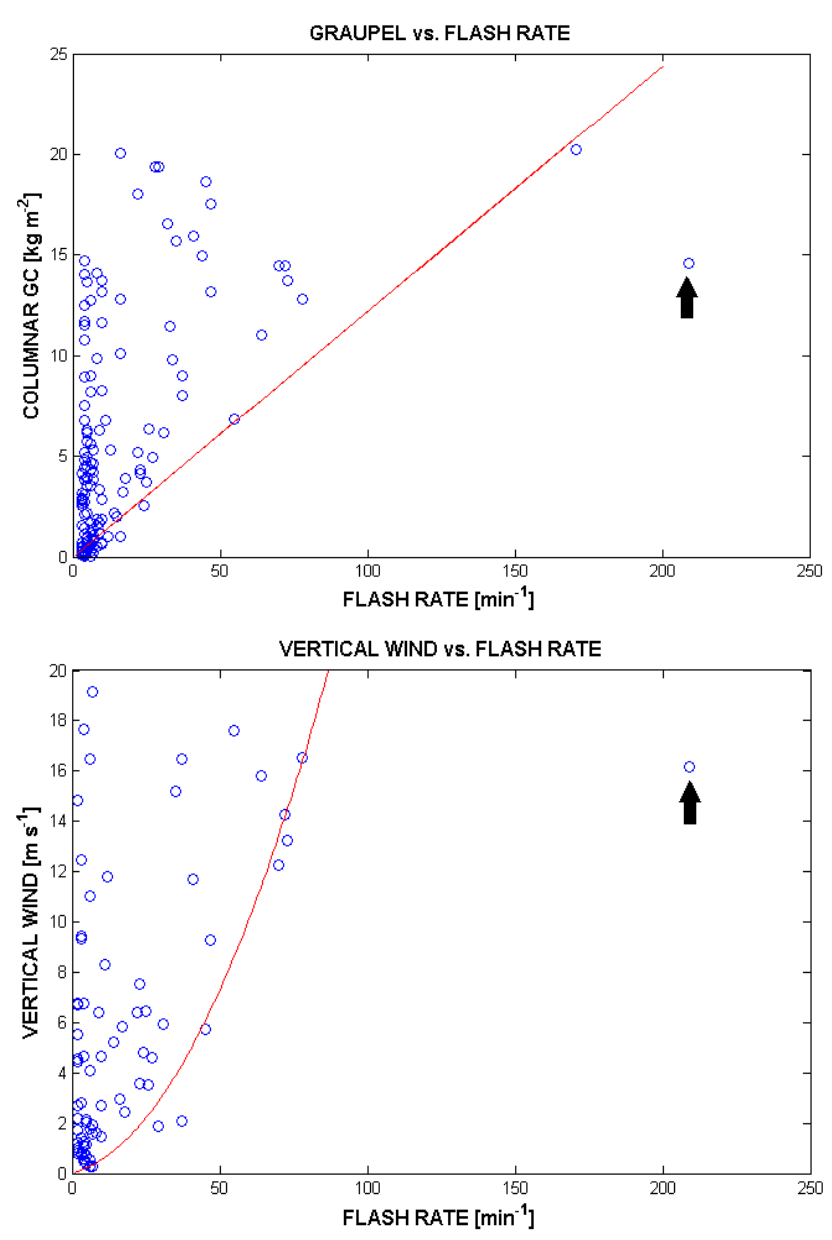

Fig. 16. Scatterplots of graupel columnar ice water content (top panel) and of vertical wind at the base of the charging zone (bottom panel) vs. total flash rate $(\mathrm{IC}+\mathrm{CG})$ sampled every minute. The red lines represent the minimum-threshold regression curves of Table 2 .

ensuring effective charge separation and instigating intense lightning activity (both IC and CG). In this case, a quadratic relationship of minimum threshold for the vertical motion at the base of the $\mathrm{CZ}$ as a function of the total flash rate has been obtained (red curve). Note that in each panel, the point indicated by the arrow represents an extreme flash rate value that occurs rarely in nature (e.g., Deierling et al., 2008; Kuhlman et al., 2006) and therefore has not been considered in our regression. Table 2 shows the coefficients of these linear and quadratic threshold relationships of $\mathrm{CIWC}_{\mathrm{g}}$ and $w_{\mathrm{CZ}}$, respectively, with total flash rate sampled every minute.

We are aware that while these quantitative minimumthreshold relationships are representative of the variability of the microphysics, thermodynamics, and electrical activity in all simulated clouds, the considered simulations might not be enough to draw definite conclusions. In addition, the results shown in the previous sections have evidenced some
Table 2. Regression curves of minimum thresholds for graupel columnar ice water content $\left(\mathrm{CIWC}_{\mathrm{g}}\right.$, in $\left.\mathrm{kg} \mathrm{m}^{-2}\right)$ and vertical wind at the bottom of the $\mathrm{CZ}\left(w_{\mathrm{CZ}}\right.$, in $\left.\mathrm{ms}^{-1}\right)$ with respect to total $(\mathrm{IC}+\mathrm{CG})$ flash rate, and relative coefficients derived from the data displayed in Fig. 16 (the red lines in the two panels).

\begin{tabular}{lcrr}
\hline Type & Function & & \\
\hline CIWC $_{\mathrm{g}}$ vs. Flash Rate & $a x+b$ & 0.1218 & 0.0 \\
$w_{\mathrm{CZ}}$ vs. Flash Rate & $a x^{2}+b_{x}$ & 0.0023 & 0.031 \\
\hline
\end{tabular}

problems in the triggering of ICs and, to a less extent, of CGs, depending on the model setup, which should be properly addressed. Thus, further verification of the minimum-threshold best fits will be subject of future studies, in which EMTM simulations of more case studies will be carried out using different functions of the breakdown electric field. Nevertheless, we would like to point out here that the existence of minimum-threshold relationships has been proposed by previous studies (e.g., Byers and Braham, 1948), and that they are quite important for several reasons. First of all, these relationships can be used to infer cloud properties based on IC and CG flash rates as observed by ground lightning networks - i.e., given a certain measured total flash rate it should be possible to infer the minimum value of graupel mass content and updraft in the observed cell, and to some extent characterize the cloud through important microphysical and dynamical properties. In this regard, it is worth noting that Cecil et al. (2005) suggest that, based on observational evidence, for a given flash rate there is a most likely vertical profile of reflectivity (precipitation). Moreover, these relationships can be very useful to identify the relevant features of the most intense cells, characterized by high flash rate values, for which the estimate of a minimum threshold for vertical motion and graupel mass can be very useful. Both the intensity of the updraft and the graupel mass content can in fact pose useful constraints in the attempt to evaluate a thunderstorm's strength and, most importantly, to estimate the precipitation rate through the use of other data (radar and/or satellite observations).

\section{Summary and conclusions}

The goal of this study was to use the EMTM 1-D model to simulate the evolution of several typical cells characterized by lightning activity and to find quantitative relationships between simulated lightning activity and cloud microphysical and thermodynamical properties. Model results were found to be highly sensitive to the environmental conditions, as well as to the initial perturbation setup of the model base-state. The response of the model was found to be consistent with the general characteristics of the noninductive electrification process, and the model simulations were shown to provide useful insight into the relationships of cloud electrification 
with strong updrafts, and, therefore, with the presence of supercooled droplets in the $\mathrm{CZ}$ (and above), high density of growing ice crystals, and graupel.

The first part of the work consisted in a comparison with real lightning data in order to verify the plausibility of the model results. To this end, two case studies were considered and the data available from the LINET ground network, which measures and discriminates between IC and CG flashes with high sensitivity, were used. It was shown that, generally, the model simulates lightning activity (IC and CG flash rate evolution and totals) with a reasonable confidence, and responds in the correct way to different environmental conditions. However, some inconsistencies in the IC vs. CG lightning distribution and temporal evolution were found, and they have been attributed mostly to the model setup assumption - particularly, the assumption of a constant breakdown electric field. Generally the EMTM model simulates better the events with strong electrical activity and therefore has shown good reliability for Case 2, which is a maritime storm characterized by a thick cumulonimbus with elevated content of moisture at low levels. Nevertheless, the IC initiation heights (sometimes lower than $5 \mathrm{~km}$ ) and the IC evolution with respect to CG have evidenced some limitations in the model. On the other hand, for Case 1, which is a weaker continental thunderstorm with elevated condensation level, the model tends to produce stronger vertical motions than those expected from the sounding. This effect is attributed to a weak entrainment parameterization that cannot reproduce adequately the loss of energy by the warm bubble due to mixing with dry air. We also found some inconsistencies in the timing and intensity of IC flashes, particularly during the initial and final phases of the weaker cells.

We then performed a thorough analysis of the microphysical, thermodynamical and electrical output of the EMTM model for the two selected case studies. These results confirm the ice-ice noninductive electrification hypothesis as an important mechanism for thunderstorm charge separation. Specifically, in agreement with previous studies, it turns out that graupel plays a key role in cloud electrification and is a good indicator of lightning activity. In particular, the IC activity in the $\mathrm{CZ}$ is strongly correlated with the graupel mixing ratio, while the highest occurrences of ICs occur in correspondence of strong updrafts. In addition, the EMTM shows that the presence of supercooled droplets at high altitudes in the cloud is another important factor leading to the presence of IC activity, even at high altitudes above the $\mathrm{CZ}$ where graupel is not present. Furthermore, the CG activity was always found to follow the first IC flashes and to be strongly linked to the presence of graupel and, therefore, to negative charge carried down to low levels by precipitating hydrometeors.

In both case studies, high density positive charge at high altitudes (10-12 km) followed the evolution of high ice crystal concentration, confirming the simulations of Mansell et al. (2010) and the analysis by Bruning et al. (2007) where upper level IC lightning was associated to the development of a significant upper level positive charge region. The classic tripole structure (positive-negative-positive), which is produced by noninductive charge separation between graupel and small ice particles, is particularly evident for the weaker continental case and ensures the presence of lower IC and CG lightning even during the weaker phase of the storm. In this regard, it is worth noting that the explicit microphysics scheme used in the EMTM allows for a better treatment of electrification processes related to crystal growth and ice multiplication processes (splintering, HallettMossop, etc.) with respect to bulk microphysics schemes, particularly single-moment schemes, where only the mass of the hydrometeor is predicted (as shown by Mansell et al., 2010). In contrast, the EMTM predicts the ice crystal concentration for different mass bins, and this result is used to derive the charge separation process in rebounding collisions with mass-binned graupel.

The EMTM results were shown to be highly sensitive not only to the environmental conditions but also to the initial cloud perturbation. Thus, in order to find quantitative relationships of cloud microphysics and thermodynamics with associated cloud electrical activity, and in order for these relationships to be representative of different kinds of clouds, several simulations, with different initial conditions for four different case studies were carried out. For all simulations, the graupel columnar ice water contents and the updrafts at the base of the $\mathrm{CZ}$ were related to the total flash rates. Two minimum-threshold relationships were found, which indicate the minimum amounts of columnar graupel and updraft that are necessary to produce any certain value of total flash rate. In other words, the EMTM model results show that a given total flash rate can be observed only if the amount of graupel and the updraft in the cloud are above a minimum value. These minimum values were also quantified as a linear and a quadratic relationship of the graupel columnar ice water content and of the updraft at the base of $\mathrm{CZ}$, respectively, with the total $(\mathrm{IC}+\mathrm{CG})$ flash rate.

Based on these relationships, the availability of good lightning networks, in particular of IC and CG lightning measurements, would potentially allow inferring important cloud microphysical and dynamical properties based uniquely on the measured total flash rate. Particularly for high values of flash rates (above $30 \mathrm{~min}^{-1}$ ), therefore for the most intense and most potentially dangerous cells, these relationships would be particularly valuable. Quantitative relationships between lightning activity and cloud microphysical (and dynamical) properties could find several applications, such as precipitation retrieval from active and passive microwave measurements, that in many cases rely on the a priori knowledge of cloud parameters. We plan in the future to verify the consistency and robustness of the relationships found in this study, by performing EMTM simulations for additional case studies, using different functions of the breakdown electric field, and by using in situ and/or radar measurements of convective 
cloud microphysical and dynamical properties in conjunction with lightning data from ground networks, such as LINET.

Acknowledgements. This research has been supported by the European Commission Sixth Framework Programme through the project "Observation, Analysis and Modeling of Lightning Activity in Thunderstorms, for use in Short Term Forecasting of Flash Floods" (FLASH) (Project Number 036852), by the European Community Initiative INTERREG III-B ARCHIMED through the project "Weather Risk Reduction in the Central and Eastern Mediterranean" (RISKMED), and by the Italian FISR-MIUR programme "Sustainable Development and Climate Changes" through the project "Aerosol Effects on Clouds and Climate" (AEROCLOUDS). The EMTM model was provided by Robert Solomon during a visit at CNR-ISAC in Rome, supported by the Italian Space Agency (ASI) and by the Italian National Group for Prevention from Hydrogeological Hazards (GNDCI). The authors wish to thank Corrado Ratto and Claudia Adamo for their helpful discussions and contributions to the manuscript. The authors wish to thank Konstantinos Lagouvardos and the other two anonymous referees for their very helpful suggestions and comments.

Edited by: S. Davolio

Reviewed by: K. Lagouvardos and two anonymous referees

\section{References}

Adamo, C., Solomon, R., Goodman, S., Cecil, D., Dietrich, S., and Mugnai, A.: Lightning and precipitation: Observational analysis of LIS and PR, in: Proceedings of the 5th EGS Plinius Conference on Mediterranean Storms, Ajaccio, Corsica, France, 1-3 October 2003, edited by: Testud, J., Mugnai, A., and Santucci, J.-F., 533-538, 2003.

Adamo, C., Goodman, S., Mugnai, A., and Weinman, J. A.: Lightning measurements from satellites and significance for storms in the Mediterranean, in: Lightning: Principles, Instruments and Applications: Review of Modern Lightning Research, edited by: Betz, H.-D., Schumann, U., and Laroche, P., Springer Science+Business Media B.V., Dordrecht, The Netherlands, ISBN: 978-1-4020-9078-3, 309-329, 2009.

Asai, T. and Kasahara, A.: A theoretical study of the compensating downward motions associated with cumulus clouds, J. Atmos Sci., 24, 487-496, 1967.

Baker, B., Baker, M. B., Jayaratne, E., Latham, J., and Saunders, C.: The influence of diffusional growth rates on the charge transfer accompanying rebounding collisions between ice crystals and hailstones, Q. J. Roy. Meteor. Soc., 113, 1193-1215, 1987.

Barthe, C. and Pinty, J.-P.: Simulation of electrified storms with comparison of the charge structure and lightning efficiency, J. Geophys. Res., 112, D19204, doi:10.1029/2006JD008241, 2007.

Barthe, C., Chong, M., Pinty, J.-P., Bovalo, C., and Escobar, J.: CELLS v1.0: updated and parallelized version of an electrical scheme to simulate multiple electrified clouds and flashes over large domains, Geosci. Model Dev., 5, 167-184, doi:10.5194/gmd-5-167-2012, 2012.

Betz, H.-D., Schmidt, K., Oettinger, W. P., and Wirz, M.: Lightning detection with 3D discrimination of intracloud and cloud- to-ground discharges, J. Geophys. Res. Lett., 31, L11108, doi:10.1029/2004GL019821, 2004.

Betz, H.-D., Schmidt, K., Fuchs, B., Oettinger, W. P., and Holler, H.: Cloud lightning: Detection and utilization for total-lightning measured in the VLF/LF regime, J. Lightning Res., 2, 1-17, 2007.

Betz, H.-D., Marshall, T. C., Stolzenburg, M., Schmidt, K., Oettinger, W. P., Defer, E., Konarski, J., Laroche, P., and Dombai, F.: Detection of in-cloud lightning with VLF/LF and VHF networks for studies of the initial discharge phase, Geophys. Res. Lett., 35, L23802, doi:10.1029/2008GL035820, 2008.

Betz, H.-D., Schmidt, K., Laroche, P., Blanchet, P., Oettinger, W. P., Defer, E., Dziewit, Z., and Konarski, J.: LINET - An international lightning detection network in Europe, Atmos. Res., 91, 564-573, 2009.

Brooks, I. M., Saunders, C. P. R., Mitzeva, R. P., and Peck, S. L.: The effect on thunderstorm charging of the rate of rime accretion by graupel, Atmos. Res., 43, 277-295, 1997.

Bruning, E. C., Rust, W. D., Schuur, T. J., MacGorman, D. R., Krehbiel, P. R., and Rison, W.: Electrical and polarimetric radar observations of a multicell storm in TELEX, Mon. Weather Rev., 135, 2525-2544, 2007.

Byers, H. R. and Braham Jr., R. R.: Thunderstorm structure and circulation, J. Meteorol., 5, 71-86, 1948.

Byers, H. R. and Braham Jr., R. R.: The Thunderstorm: Final Report of the Thunderstorm Project, US Government Printing Office, Washington, DC, USA, 282 pp., 1949.

Cecil, D. J., Goodman, S. J., Boccippio, D. J., Zipser, E. J., and Nesbitt, S. W.: Three years of TRMM precipitation features, Part I: Radar, radiometric, and lightning characteristics, Mon. Weather Rev., 133, 543-566, 2005.

Chalmers, J. A.: Atmospheric Electricity, Pergamon press, New York, USA, 515 pp., 1967.

Deierling, W. and Petersen, W. A.: Total lightning activity as an indicator of updraft characteristics, J. Geophys. Res., 113, D16210, doi:10.1029/2007JD009598, 2008.

Deierling, W., Petersen, W. A., Latham, J., Ellis, S., and Christian, H.: The relationship between lightning activity and ice fluxes in thunderstorms, J. Geophys. Res., 113, D15210, doi:10.1029/2007JD009700, 2008.

Dye, J. E., Winn, W. P., Jones, J. J., and Breed, D. W.: The electrification of New Mexico thunderstorms, Part 1: The relationship between precipitation development and the onset of electrification, J. Geophys. Res., 94, 8643-8656, 1989.

Fierro, A. O., Gilmore, M. S., Mansell, E. R., Wicker, L. J., and Straka, J. M.: Electrification and lightning in an idealized boundary-crossing supercell simulation of 2 June 1995, Mon. Weather Rev., 134, 3149-3172, 2006.

Gardiner, B., Lamb, D., Pitter, R., Hallet, J., and Saunders, C.: Measurements of initial potential gradients and particles charges in a Montana summer thunderstorm., J. Geophys., Res., 90, 60796086, 1985.

Gillespie, D. T.: Three models for the coalescence growth of drops, J. Atmos. Sci., 32, 600-607, 1975.

Goodman, S. J., Buechler, D., and McCaul, E.: Lightning, in: Our Changing Planet: The View from Space, edited by: King, M., Parkinson, C., Partington, K., and Williams, R., Cambridge University Press, Cambridge, United Kingdom, 44-52, 2007. 
Gungle, B. and Krider, E. P.: Cloud-to-ground lightning and surface rainfall in warm-season Florida thunderstorms, J. Geophys. Res., 111, D19203, doi:10.1029/2005JD006802, 2006.

Hallett, J. and Mossop, S. C.: Production of secondary ice particles during the riming process, Nature, 249, 26-28, 1974.

Helsdon, J. H., Wu, G., and Farley, R. D.: An intracloud lightning parameterization scheme for a storm electrification model, J. Geophys. Res., 97, 5865-5884, 1992.

Jayaratne, E. R., Saunders, C. P. R., and Hallett, J.: Laboratory studies of the charging of soft-hail during ice crystal interactions, Q. J. Roy. Meteor. Soc., 109, 609-630, 1983.

Jennings, S. G.: Electrical charging of water drops in polarizing electric fields, J. Electrostat., 1, 15-25, 1975.

Katsanos, D., Lagouvardos, K., Kotroni, V., and Argiriou, A. A.: The relationship of lightning activity with microwave brightness temperatures and spaceborne radar reflectivity profiles in the central and eastern Mediterranean, J. Appl. Meteorol. Clim., 46, 1901-1912, 2007.

Keith, H. W. and Saunders, C. P. R.: Charge transfer during multiple large ice-crystal interactions with a riming target, J. Geophys. Res., 94, 13103-13106, 1989.

Kempf, M. N. and Krider, E. P.: Cloud-to-ground and surface rainfall during the great flood of 1993, Mon. Weather Rev., 131, 1140-1149, 2003.

Klemp, J. B. and Wilhelmson, R. B.: The simulation of threedimensional convective storm dynamics, J. Atmos. Sci., 35, 1070-1096, 1978.

Kotroni, V. and Lagouvardos, K.: Lightning occurrence in relation with elevation, terrain slope and vegetation cover in the Mediterranean, J. Geophys. Res., 113, D21118, doi:10.1029/2008JD010605, 2008.

Krehbiel, P.: An analysis of the electric field change produced by lightning, Ph.D. Dissertation, Institute of Science and Technology, University of Manchester, Manchester, UK, 400 pp., 1981.

Kuhlman, K. M., Ziegler, C. L., Mansell, E. R., MacGorman, D. R., and Straka, J. M.: Numerically simulated electrification and lightning of the 29 June 2000 STEPS supercell storm, Mon. Weather Rev., 134, 2734-2757, 2006.

Lagouvardos, K., Kotroni, V., Betz, H.-D., and Schmidt, K.: A comparison of lightning data provided by ZEUS and LINET networks over Western Europe, Nat. Hazards Earth Syst. Sci., 9, 1713-1717, doi:10.5194/nhess-9-1713-2009, 2009.

Lang, T. J. and Rutledge, S. A.: Relationships between convective storm kinematics, precipitation, and lightning, Mon. Weather Rev., 130, 2492-2506, 2002.

Latham, J., Blyth, A. M., Christian, H. J., Deierling, W., and Gadian, A. M.: Determination of precipitation rates and yields from lightning measurements, J. Hydrol., 288, 13-19, 2004.

Lynn, B., Yair, Y., Price, C., Kelman, G., and Clark, A. J.: Predicting Cloud-to-Ground and Intracloud lightning in weather forecast models, Weather Forecast., 27, 1470-1488, doi:10.1175/WAFD-11-00144.1, 2012.

MacGorman, D. R. and Nielsen, K. E.: Cloud-to-ground lightning in a tornadic storm on 8 May 1986, Mon. Weather Rev., 119, 1557-1574, 1991.

MacGorman, D. R., Straka, J. M., and Ziegler, C. L.: A lightning parameterization for numerical cloud models, J. Appl. Meteorol., 40, 459-478, 2001.
Mansell, E. R., MacGorman, D. R., Ziegler, C. L., and Straka, J. M.: Simulated three-dimensional branched lightning in a numerical thunderstorm model, J. Geophys. Res., 107, 12 pp., doi:10.1029/2000JD000244, 2002.

Mansell, E. R., MacGorman, D. R., Ziegler, C. L., and Straka, J. M.: Charge structure and lightning sensitivity in a simulated multicell thunderstorm, J. Geophys. Res., 110, D12101, doi:10.1029/2004JD005287, 2005.

Mansell, E. R., Ziegler, C. L., and Bruning, E. C.: Simulated electrification of a small thunderstorm with two-moment bulk microphysics, J. Atmos. Sci., 67, 171-194, 2010.

Marshall, T. C., McCarthy, M. P., and Rust, D. W.: Electric field magnitudes and lightning initiation in thunderstorms, J. Geophys., Res., 100, 7097-7103, 1995a.

Marshall, T. C., Rison, W., Rust, W. D., Stolzenburg, M., Willet, J. C., and Winn, W. P.: Rocket and balloon observations of electric field in two thunderstorm, J. Geophys., Res., 100, 20815-20828, 1995b.

Mason, B. L. and Dash, J. G.: Charge and mass transfer in ice-ice collisions: experimental observations of a mechanism in thunderstorm electrification, J. Geophys. Res., 105, 20185-20192, 2000.

McCaul, E. W., Goodman, S. J., La Casse, K. M., and Cecil, D. J.: Forecasting lightning threat using cloud-resolving model simulations, Weather Forecast., 24, 709-729, 2009.

Nelson, J. and Baker, M.: Charging of ice-vapor interfaces: applications to thunderstorms, Atmos. Chem. Phys., 3, 1237-1252, doi:10.5194/acp-3-1237-2003, 2003.

Norville, K., Baker, M., and Latham, J.: A numerical study of thunderstorm electrification: Model development and case study, J. Geophys. Res., 96, 7463-7481, 1991.

Pessi, A. and Businger, S.: Relationships among lightning, precipitation, and hydrometeor characteristics over the North Pacific Ocean, J. Appl. Meteorol. Clim., 48, 833-848, 2009.

Petersen, W. A., Christian, H. J., and Rutledge, S. A.: TRMM observations of the global relationship between ice water content and lightning, Geophys. Res. Lett., 32, L14819, doi:10.1029/2005GL023236, 2005.

Pineda, N., Rigo, T., Bech, J., and Soler, X.: Lightning and precipitation relationship in summer thunderstorms: Case studies in the North Western Mediterranean region, Atmos. Res., 85, 159-170, 2007.

Price, C. and Federmesser, B.: Lightning-rainfall relationships in Mediterranean winter thunderstorms, Geophys. Res. Lett., 33, L07813, doi:10.1029/2005GL024794, 2006.

Price, C. and Rind, D.: A simple lightning parameterization for calculating global lightning distributions, J. Geophys. Res., 97, 9919-9933, doi:10.1029/92JD00719, 1992.

Price, C., Yair, Y., Mugnai, A., Lagouvardos, K., Llasat, M. C., Michaelides, S., Dayan, U., Dietrich, S., Di Paola, F., Galanti, E., Garrote, L., Harats, N., Katsanos, D., Kohn, M., Kotroni, V., Llasat-Botija, M., Lynn, B., Mediero, L., Morin, E., Nicolaides, K., Rozalis, S., Savvidou, K., and Ziv, B.: Using lightning data to better understand and predict flash floods in the Mediterranean, Surv. Geophys., 32, 733-751, 2011.

Reynolds, S. E., Brook, M., and Gourley, F.: Thunderstorm charge separation, J. Meteorol., 14, 426-436, 1957.

Rison, W., Thomas, R. J., Krehbiel, P. R., Hamlin, T., and Harlin, J.: A GPS-based three-dimensional lightning mapping system: Initial observations in central New Mexico, Geophys. Res. Lett. 
26, 3573-3576, 1999.

Saunders, C. P. R.: Charge separation mechanisms in clouds, Space Sci. Rev., 137, 335-353, doi:10.1007/s11214-008-9345-0, 2008.

Saunders, C. P. R. and Peck, S. L.: Laboratory studies of the influence of the rime accretion rate on charge transfer during crystal/graupel collisions, J. Geophys. Res., 103, 13949-13956, 1998.

Saunders, C. P. R., Keith, W. D., and Mitzeva, R. P.: The effect of liquid water on thunderstorm charging, J. Geophys. Res., 96, 11007-11017, 1991.

Schultz, C. J., Petersen, W. A., and Carey, L. D.: Lightning and severe weather: A comparison between total and cloud-to-ground lightning trends, Weather Forecast., 26, 744-755, 2011.

Solomon, R.: A modelling study of thunderstorm electrification and lightning flash rate, PhD Dissertation, Atmospheric Science Program, University of Washington, Seattle, Washington, USA, 110 pp., 1997.

Solomon, R. and Baker, M.: A one-dimensional lightning parameterization, J. Geophys. Res., 101, 14983-14990, doi:10.1029/96JD00941, 1996.

Solomon, R., Medaglia, C. M., Adamo, C., Dietrich, S., and Mugnai, A.: Relating cloud microphysical properties and lightning: Model analysis of an extreme hailstorm, in: Proceedings of the 5th EGS Plinius Conference on Mediterranean Storms, Ajaccio, Corsica, France, 1-3 October 2003, edited by: Testud, J., Mugnai, A., and Santucci, J.-F., 499-505, 2003.

Solomon, R., Medaglia, C. M., Adamo, C., Dietrich, S., Mugnai, A., and Biader Ceipidor, U.: An explicit microphysics thunderstorm model, Int. J. Model. Simul., 25, 112-118, 2005.

Soula, S. and Chauzy, S.: Some aspects of the correlation between lightning and rain activities in thunderstorms, Atmos. Res., 52, 355-373, 2001.

Soula, S., Sauvageot, H., Molini, G., Mesnard, F., and Chauzy, S.: The CG lightning activity of a storm causing a flash-flood, Geophys. Res. Lett., 25, 1181-1184, doi:10.1029/98GL00517, 1998.
Takahashi, T.: Riming electrification as a charge generation mechanism in thunderstorm, J. Atmos. Sci., 35, 1536-1548, 1978.

Tapia, A., Smith, J. A., and Dixon, M.: Estimation of convective rainfall from lightning observations, J. Appl. Meteorol., 37, 1497-1509, 1998.

Taylor, G. R.: Sulfate production and deposition in mid-latitude continental cumulus clouds, Part I: Cloud model formulation and base run analysis, J. Atmos. Sci., 46, 1971-1990, 1989.

Williams, E. R., Boldi, B., Matlin, A., Weber, M., Hodanish, S., Sharp, D., Goodman, S. J., Raghavan, R., and Buechler, D.: The behavior of total lightning activity in severe Florida thunderstorms, Atmos. Res., 51, 245-265, 1999.

Wilson, C. T. R.: Some thunderstorm problems, J. Franklin Inst., 208, 1-12, 1929.

Wiens, K. C., Rutledge, S. A., and Tessendorf, S. A.: The 29 June 2000 supercell observed during STEPS, Part II: Lightning and charge structure, J. Atmos. Sci., 62, 4151-4177, 2005.

Yair, Y., Lynn, B., Price, C., Kotroni, V., Lagouvardos, K., Morin, E., Mugnai, A., and Llasat, M. C.: Predicting the potential for lightning activity in Mediterranean storms based on the Weather Research and Forecasting (WRF) model dynamic and microphysical fields, J. Geophys. Res., 115, D04205, doi:10.1029/2008JD010868, 2010.

Yau, M.: A two-cylinder model of cumulus cells and its application in computing cumulus transports, J. Atmos. Sci., 37, 2470-2485, 1980.

Zhou, Y., Qie, X., and Soula, S.: A study of the relationship between cloud-to-ground lightning and precipitation in the convective weather system in China, Ann. Geophys., 20, 107-113, doi:10.5194/angeo-20-107-2002, 2002.

Ziegler, C. L., MacGorman, D. R., Dye, J. E., and Ray, P. S.: A model evaluation of noninductive graupel-ice charging in the early electrification of a mountain thunderstorm, J. Geophys. Res., 96, 12833-12855, 1991. 